\title{
QUEEN'S
UNIVERSITY
BELFAST
}

\section{Microwave-assisted Cu-catalyzed Ullmann ether synthesis in a continuous-flow milli-plant}

Benaskar, F., Patil, N. G., Meuldijk, J., Hulshof, L. A., Hessel, V., Schouten, J. C., Engels, V., Wheatley, A. E. H., \& Rebrov, E. V. (2012). Microwave-assisted Cu-catalyzed Ullmann ether synthesis in a continuous-flow milliplant. Chemical Engineering Journal, 207-208, 426-439. https://doi.org/10.1016/j.cej.2012.06.147

Published in:

Chemical Engineering Journal

Document Version:

Peer reviewed version

Queen's University Belfast - Research Portal:

Link to publication record in Queen's University Belfast Research Portal

\section{Publisher rights}

This is the author's version of a work that was accepted for publication in Chemical Engineering Journal. Changes resulting from the publishing process, such as peer review, editing, corrections, structural formatting, and other quality control mechanisms may not be reflected in this document. Changes may have been made to this work since it was submitted for publication. A definitive version was subsequently published in Chemical Engineering Journal, VOLS 207-208, 10/2012

\section{General rights}

Copyright for the publications made accessible via the Queen's University Belfast Research Portal is retained by the author(s) and / or other copyright owners and it is a condition of accessing these publications that users recognise and abide by the legal requirements associated with these rights.

Take down policy

The Research Portal is Queen's institutional repository that provides access to Queen's research output. Every effort has been made to ensure that content in the Research Portal does not infringe any person's rights, or applicable UK laws. If you discover content in the Research Portal that you believe breaches copyright or violates any law, please contact openaccess@qub.ac.uk. 


\section{Accepted Manuscript}

Microwave-assisted Cu-catalyzed Ullmann ether synthesis in a continuous-flow milli-plant

F. Benaska, N.G. Patil, V. Engels, E.V. Rebrov, J. Meuldijk, L.A. Hulshof, V. Hessel, A.E.H. Wheatley, J.C. Schouten

PII:

S1385-8947(12)00884-4

DOI: http://dx.doi.org/10.1016/j.cej.2012.06.147

Reference: CEJ 9508

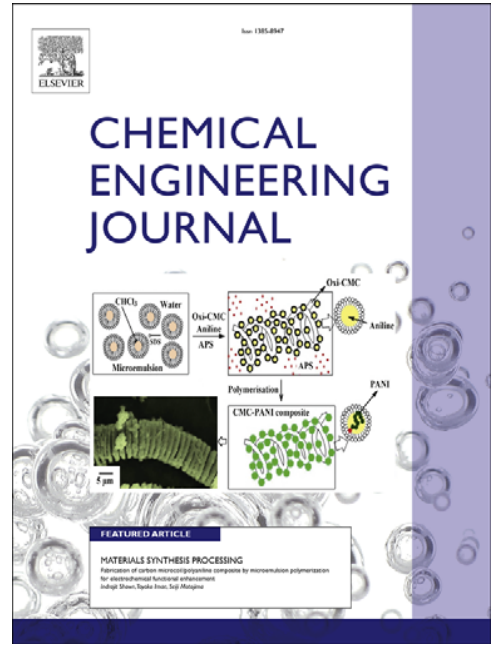

To appear in:

Chemical Engineering Journal

Please cite this article as: F. Benaska, N.G. Patil, V. Engels, E.V. Rebrov, J. Meuldijk, L.A. Hulshof, V. Hessel, A.E.H. Wheatley, J.C. Schouten, Microwave-assisted Cu-catalyzed Ullmann ether synthesis in a continuous-flow milli-plant, Chemical Engineering Journal (2012), doi: http://dx.doi.org/10.1016/j.cej.2012.06.147

This is a PDF file of an unedited manuscript that has been accepted for publication. As a service to our customers we are providing this early version of the manuscript. The manuscript will undergo copyediting, typesetting, and review of the resulting proof before it is published in its final form. Please note that during the production process errors may be discovered which could affect the content, and all legal disclaimers that apply to the journal pertain. 


\title{
Microwave-assisted Cu-catalyzed Ullmann ether synthesis in a
}

\section{continuous-flow milli-plant}

\author{
F. Benaskar, ${ }^{a}$ N.G Patil, ${ }^{a}$ V. Engels, ${ }^{b}$ E.V. Rebrov, ${ }^{c}$ J. Meuldijk, ${ }^{a}$ L. A. Hulshof, ${ }^{a}$ \\ V. Hessel, ${ }^{a}$ A.E.H. Wheatley, ${ }^{b}$ J.C. Schouten, ${ }^{a, *}$
}

${ }^{a}$ Laboratory of Chemical Reactor Engineering, Department of Chemical Engineering and Chemistry, Eindhoven University of Technology, P.O. Box 513, 5600 MB, Eindhoven, The Netherlands.

${ }^{b}$ Department of Chemistry, University of Cambridge, Lensfield Road, Cambridge, CB2 1EW, UK

'School of Chemistry and Chemical Enginering, Queen's University Belfast, Stranmillis Road, Belfast, BT9 5AG, UK.

\begin{abstract}
The combination of milli-scale processing and microwave heating has been investigated for the $\mathrm{Cu}$-catalyzed Ullmann etherification in fine-chemical synthesis, providing improved catalytic activity and selective catalyst heating. Wall-coated and fixed-bed milli-reactors were designed and applied in the $\mathrm{Cu}$-catalyzed Ullmann-type $\mathrm{C}-\mathrm{O}$ coupling of phenol and 4chloropyridine. In a batch reactor the results show clearly increased yields for the microwave heated process at low microwave powers, whereas high powers and catalyst loadings reduced the benefits of microwave heating. Slightly higher yields were found in the $\mathrm{Cu} / \mathrm{ZnO}$ wallcoated as compared to the $\mathrm{Cu} / \mathrm{TiO}_{2}$ fixed-bed flow-reactor. The benefit here is that the reaction occurs at the surface of the metal nanoparticles confined within a support film making the nano-copper equally accessible. Catalyst deactivation was mainly caused by $\mathrm{Cu}$ oxidation and coke formation; however, at longer process times leaching played a significant role. Catalyst
\end{abstract}


activity could partially be recovered by removal of deposited by-product by means of calcination. After $6 \mathrm{~h}$ on-stream the reactor productivities were 28.3 and $55.1 \mathrm{~kg}_{\text {prod }} /\left(\mathrm{m}_{\mathrm{R}}{ }^{3} \cdot \mathrm{hr}\right)$ for the fresh $\mathrm{Cu} / \mathrm{ZnO}$ wall-coated and $\mathrm{Cu} / \mathrm{TiO}_{2}$ fixed-bed reactor, respectively. Comparison of single- and multimode microwaves showed a three-fold yield increase for single-mode microwaves. Control of nanoparticles size and loading allows to avoid high temperatures in a single-mode microwave field and provides a novel solution to a major problem for combining metal catalysis and microwave heating. Catalyst stability appeared to be more important and provided two-fold yield increase for the $\mathrm{CuZn} / \mathrm{TiO}_{2}$ catalyst as compared to the $\mathrm{Cu} / \mathrm{TiO}{ }_{2}$ catalyst due to stabilized copper by preferential oxidation of the zinc. For this catalyst a threefold yield increase was observed in single-mode microwaves which, to the best of our knowledge, led to a not yet reported productivity of $172 \mathrm{~kg}_{\text {prod }} /\left(\mathrm{m}_{\mathrm{R}}^{3} \cdot \mathrm{hr}\right)$ for the microwave and flow Ullmann C-O coupling.

Keywords: Process intensification, flow-chemistry, fine-chemicals, micro fixed-bed reactors, wall-coated reactors, Ullmann-type coupling reaction

*Corresponding author. Telephone: +31 (0)40 2472850. Fax: +31 (0)40 2446653.

E-mail address: j.c.schouten@tue.nl 


\section{Introduction}

Microwave and micro-processing in flow systems. Flow-chemistry in organic synthesis using micro processing is now well-established as a technology for continuous production of complex organic molecules [1-6]. Pd and Cu-catalyzed C-C, C-N, C-S and C-O coupling reactions and $\mathrm{Cu}$-catalyzed Simmons-Smith cyclopropanation reactions have been widely developed and applied in flow processes [7]. Moreover, combining milli-reactor operation and microwave heating as an alternative energy source, allows the accurate control of temperatures and residence times in chemical processes. This consequently enhances control of reactor performance in terms of conversion and product selectivity [8-10]. In particular, regarding the twelve principles of green chemistry, process intensification and novel process windows provide many options by which to meet sustainable processing criteria [11-15].

The concept of combining microwave and flow-chemistry to conduct novel process operations in organic synthesis has recently attracted interest from a wide spectrum of research disciplines in both industry and academia [16-20]. Kappe and co-workers reported work on combined microwaves and flow systems using meso-scale reactors and microwave heating [21]. The authors employed the concepts of "Novel Process Windows", as introduced by Hessel et al., and discussed the multiple opportunities for operating and controlling organic reactions at elevated temperatures and pressures [22, 23]. Organ and co-workers also contributed to state-of-art microwave-assisted capillary-type flow-reactors for metal-catalyzed organic reactions [24, 25]. Many examples have been reported of dedicated flow systems being used in combination with microwave heating for large-scale synthesis and industrial applications [26]. AstraZeneca studied various examples of microwave-assisted flow-synthesis for pharmaceuticals, leading to rather high productivities [27]. Earlier, Moseley et al. developed automated microwave "stop-flow" reactors that provided competitive productivities as compared to typical batch-scale reactions [28, 29]. The current successes in 
combining microwave heating and flow systems, however, have mainly been achieved using multimode microwave cavities. These suffer from a non-uniform microwave field and a limited microwave penetration depth, resulting in an inhomogeneous temperature distribution. The use of single-mode microwave cavities in flow-chemistry, which provide a highly uniform microwave field, is currently an emerging field of investigation for efficient reaction operation.[30-32] Since for most organic solvents the penetration depth of microwaves is of the order of centimetres the optimum microwave-assisted reactor for organic reactions is characterized by reactors with the same or smaller dimensions $[33,34]$. At these reactor sizes microwaves, acting as a volumetric heating source, do not suffer from heat-transfer resistance and, combined with a proper reaction medium, provide opportunities to heat the reaction mixture rapidly and efficiently (Figure 1a). Meanwhile, micro- and milli-reactors themselves are characterized by their low resistance to heat transfer. Taken together, these observations suggest the potential for highly efficient microwave assisted reactions using combined microwave milli-reactors that are optimized with respect to heat supply and release (Figure 1b).

Figure 1

Recently, Patil et al. have demonstrated the effect of shape and dimensions of a milli-reactor setup on controlled and efficient microwave heating in a single-mode cavity [31]. The results provided experimental evidence of complete microwave penetration in a milli-sized tubular reactor in the direction perpendicular to the fluid flow. This resulted in rapid and controlled heating without the development of significant radial temperature gradients in the milli-sized flow-reactors used. Nevertheless, unresolved drawbacks, such as (a) limited microwave penetration depth, (b) high equipment costs, (c) difficult temperature measurement and control and (d) restriction to the use of polar solvents/reactants specific to each process, still hamper 
applications in industrial practice. The penetration depth limitations and the restriction to the use only of polar solvents can be circumvented in metal-catalyzed reactions where microwave heating occurs via interaction of the electric/magnetic component of the microwaves with the metals. This resultant selective metal heating provides a unique opportunity to address these limitations in microwave heated reactors [35].

Cu-catalyzed coupling reactions in flow-processing. In 2010 the Nobel Prize for Chemistry was awarded to the pioneers of heterogeneously catalyzed cross-coupling reactions that have been key to organic synthesis during the last half century [36-42]. However, the Ullmann-type coupling reaction using a $\mathrm{Cu}$ catalyst provides significant economic advantages over Pd-catalyzed cross-coupling processes due to the much lower catalyst price and scarcity of $\mathrm{Cu}$ (see Scheme 1) [43].

\section{Scheme 1}

The Ullmann-type $\mathrm{C}-\mathrm{C}, \mathrm{C}-\mathrm{O}$ and $\mathrm{C}-\mathrm{N}$ coupling reactions, discovered more than a century ago by Ullmann and Goldberg, have recently encountered a renaissance, mainly as a result of the exploitation of highly efficient copper-based catalysts [44-52]. However, these Ullmanntype coupling reactions still suffer from the need for harsh reaction conditions, the use of high levels of catalyst (50-100 mol\%) and also the need to use relatively reactive and expensive aryl halides. Reaction intensification, improvement of selectivity and the development of more stable catalysts represent the current challenges, and catalytic milli-reactors promise to address these challenges. In flow-processing, the major issue is to avoid the use of catalyst slurries by supporting catalysts on the reactor wall or by employing micro-structured fixed-beds. [53]. Moreover, stable catalyst performance in terms of activity and selectivity in a heterogeneously catalyzed flow process brings a major cost benefit in comparison to the use of homogeneous or slurry catalysts, which require expensive catalyst recovery procedures [43]. 
When providing a catalyst for reaction, it is necessary also to consider how energy is supplied to the catalyst surface, in particular because the efficiency of this process is governed by classical heat-transfer limitations. However, metal catalysts are known to absorb energy rapidly under microwave irradiation and, as a result, to couple the microwave energy selectively to the catalyst particles, leaving the surrounding environment less or even unheated [54-57]. In this way, microwaves selectively heat the reaction system at the locus of the reaction and so enhance efficiency as well as activity and conversion. A fast rise in the temperature of the nano-catalyst combined with a relatively low solvent bulk temperature leads to highly advantageous reaction conditions. This is especially true when the active copper catalyst, e.g. in Ullmann coupling, is supported by a non-magnetic matrix, such as $\mathrm{TiO}_{2}, \mathrm{SiO}_{2}$ or $\mathrm{ZnO}$, as described by Walton et al. [58-60]. In metals with magnetic character, rapid microwave absorption results from so-called eddy currents and magnetic reversal loss mechanisms when micron-sized particles are present $[61,62]$. In addition, the strong coupling of these metals with the microwave field has been reported, providing very fast heating but, dependent on particle size, unfortunately also arcing. [62, 63]. As a result, it is of importance, not only for sustainable use of the catalyst, but also for selective microwave absorption, to synthesize active $\mathrm{Cu}$ particles of the desired nano-size and with a uniform size distribution. We have recently reported on the development of monometallic and bimetallic Cu-based nanoparticles with a narrow size-distribution and a high resistance to oxidation during Ullmann-type reaction. [64]. Additionally, the use of microwave energy in the Ullmann-type reaction was reported for these nano-catalysts. These results have now been developed in terms of flow-chemistry [65].

We propose here an integrated system which synergizes the benefits of microwave systems (as a novel heating technology) and milli-processing (as a novel reactor technology) in flowsynthesis. A tubular milli-reactor was designed, where the catalyst and support were coated 
either onto the reactor wall or onto a packing material composed of spherical glass beads, leading to a wall-coated or a fixed-bed milli-reactor, respectively. More important, however, was the use of heterogeneous copper which, as a "metallic microwave-absorber", permitted selective heating of the catalyst surface and thus provided improved activity.

\section{Materials and methods}

\subsection{Chemical protocol}

Ullmann $\mathrm{C}-\mathrm{O}$ coupling reactions. 4-Chloropyridine was prepared from 4-chloropyridine $\mathrm{HCl}$ salt (Sigma-Aldrich, 99\%) by neutralization using a $2.5 \mathrm{M}$ aqueous solution of $\mathrm{K}_{2} \mathrm{CO}_{3}$, followed by filtration, extraction with diethyl ether (Sigma-Aldrich, anhydrous $>99 \%$ ), solvent evaporation and drying. Potassium phenolate was synthesized by reacting phenol with potassium tert-butoxide (Sigma-Aldrich, reagent grade 95\%) in THF (Sigma-Aldrich, inhibitorfree and anhydrous, $\geq 99.9 \%$ ) at $60{ }^{\circ} \mathrm{C}$. After solvent evaporation and vacuum drying, potassium phenolate was obtained quantitatively as a yellowish powder. For the activity experiments $20 \mathrm{~g}(0.15 \mathrm{~mol})$ of potassium phenolate and $0.40 \mathrm{~g}(0.0015 \mathrm{~mol})$ of 18-crown-6 (Aldrich $>99.0 \%$ ) were dissolved in $80 \mathrm{~mL} N, N$-dimethylacetamide (DMA, Sigma-Aldrich, CHROMASOLV $^{\circledR}$ Plus, for HPLC, $\geq 99.9 \%$ ) in a continuously stirred vessel at $50-60{ }^{\circ} \mathrm{C}$. After a solution was obtained, $11.4 \mathrm{~g}(0.1 \mathrm{~mol})$ of 4-chloropyridine and $1.9 \mathrm{~g}(0.01 \mathrm{~mol})$ of tetradecane as internal standard (Fluka, analytical standard) were mixed separately with $20 \mathrm{~mL}$ DMA and slowly fed to the storage vessel. The reactants were pumped into the flow-through

reactor (See Supporting Information). For batch experiments, the reactants were mechanically mixed at $500 \mathrm{rpm}$ in the abovementioned concentrations, heated until the reaction temperature was reached and then the copper powder (99 wt.\%, Aldrich) was added as the catalyst (10 mol\% with respect to 4-chloropyridine).

\subsection{Catalyst synthesis}


Copper nanoparticles. $\mathrm{Cu}$ nanoparticles were synthesized as previously reported from copper(II) sulfate pentahydrate, sodium hypophosphite monohydrate and PVP (M(average) $=$ 40,000) $[64,66]$. The synthesis of bimetallic CuZn nanoparticles was based on the use of copper sulphate pentahydrate and zinc(II) chloride following our previous work [52]. $\mathrm{TiO}_{2}$ based fixed-bed catalyst. Support synthesis employed titanium(IV) ethoxide (99.99\%), isopropanol (anhydrous, 99.5\%), hexamethylenetetramine (HMTA, puriss. p.a., $\geq 99.5 \%$ ). 250 $\pm 12 \mu \mathrm{m}$ spherical $\mathrm{SiO}_{2}$-beads (E\&R Chemicals \& Equipment B.V.) were used as support carriers [67]. These beads were first coated with mesoporous $\mathrm{TiO}_{2}$ by dip-coating, after which the $\mathrm{Cu}$ nanoparticles were coated by wet impregnation (See Supporting Information). A total of $0.75 \mathrm{~g}$ (3.29 mmol) titanium(IV) ethoxide (Ti(OEt) $)_{4}$ ) was added to $20 \mathrm{~g}$ of glass beads, followed by vacuum solvent removal at $60{ }^{\circ} \mathrm{C}$, overnight drying at $80{ }^{\circ} \mathrm{C}$ and calcination at $120-350^{\circ} \mathrm{C}$ for $12 \mathrm{~h}$ (heating/cooling rate: $10^{\circ} \mathrm{C} / \mathrm{min}$ ) (See Supporting Information).

$\mathrm{ZnO}$ based wall-coated catalyst. For the growth of $\mathrm{ZnO}$ nanowires on the internal reactor wall, a seed layer of $\mathrm{ZnO}$ nanoparticles (mean size $\sim 100 \mathrm{~nm}$ ) was deposited by circulation of a nanoparticle suspension in ${ }^{\mathrm{i}} \mathrm{PrOH}$ for $48 \mathrm{~h}$ (flow speed $1.5 \mathrm{~mL} / \mathrm{min}$ ). Subsequently, the system was flushed with pure $\mathrm{PrOH}$ for $30 \mathrm{~min}$. After drying, an equimolar aqueous solution of HMTA and $\mathrm{Zn}\left(\mathrm{NO}_{3}\right)_{2}(0.025 \mathrm{M})$ was pre-heated to $90{ }^{\circ} \mathrm{C}$ and circulated through the system for $5 \mathrm{~h}$, followed by flushing with ${ }^{\mathrm{i}} \mathrm{PrOH}$ for $1 \mathrm{~h}(0.5 \mathrm{~mL} / \mathrm{min})$. The tube was pre-dried and heated in a muffle furnace $\left(80^{\circ} \mathrm{C}\right)$ for $1 \mathrm{~h}$. The reactor was coated with copper nanoparticles by flowing $50 \mathrm{~mL}$ of a $\mathrm{Cu}$ nanoparticle suspension in anhydrous methanol (metal mass concentration: $0.25 \mathrm{mg} / \mathrm{mL}$ ) through the reactor tube at a flow speed of $1 \mathrm{~mL} / \mathrm{min}$. After solvent evaporation, the reactor was calcined at $350{ }^{\circ} \mathrm{C}$ for $12 \mathrm{~h}$ (heating/cooling rate: 10 $\left.{ }^{\circ} \mathrm{C} / \mathrm{min}\right)$.

\subsection{Wall-coated and fixed-bed tubular reactors in oil-bath and microwave heating} experiments 
Quartz-glass tubular milli-reactors $\left(\mathrm{L}=1.2-1.5 \mathrm{~m}, \mathrm{~d}_{\text {in }}=1-3 \mathrm{~mm}\right.$ and $\left.\mathrm{d}_{\text {ou }}=5 \mathrm{~mm}\right)$ were either packed with catalyst coated glass beads or wall-coated with the catalyst. Figure 2 shows the design procedure for both (wall-coated and fixed) reactor configurations.

Figure 2

Reactor inlet and outlet were extended to enable an easy connection and disconnection to the pump head, sampler and outlet valve. The flowrate was varied $(\mathrm{Fv}=5-80 \mathrm{~mL} / \mathrm{h})$ to obtain desired residence times. Fixed-bed systems were prepared by packing the coated beads into the tube $\left(\mathrm{V}_{\text {total }}=10.10 \mathrm{~mL}\right)$ to mimic a micro fixed-bed reactor with a bead interstitial spacing in the range $10-50 \mu \mathrm{m}$. The resulting bed void provided an experimentally determined liquid volume of $\mathrm{V}_{\text {liq }}=3.34 \mathrm{~mL}$ with a catalyst loading of $2.5 \mathrm{mg} / \mathrm{mL}_{\text {liq }}$, which was comparable to a batch reactor catalyst loading of $2.7 \mathrm{mg} / \mathrm{mL}_{\text {liq. }}$ As shown in Figure 3, the reactor was placed either vertically in an oil-bath (Lauda Ecoline Staredition 012, type E312, $2.3 \mathrm{~kW}$ with a halfsynthetic oil medium) or horizontally in a multimode microwave cavity (Milestone Multimode Microwave, type ETHOS $2.45 \mathrm{GHz}, 2.5 \mathrm{~kW}$ ). The pre-mixed (mechanical) and pre-heated $\left(50{ }^{\circ} \mathrm{C}\right)$ reactant solution was fed into the reactor through a syringe pump $(1000 \mathrm{D}$; Teledyne ISCO Inc., Lincoln, NE/USA), which could be operated at pressures from 1 to 40 bar (see Figure 2, left). An argon injector was placed in the supply vessel to maintain inert atmosphere. At the reactor outlet, a T-splitter (T-junction, Swagelok, 1/8 in.) was connected to the sampler.

Figure 3

For the oil-bath reactions, temperatures were measured using K-type thermocouples (Voltcraft K204 data logger) placed inside the oil-bath and at the outlet of the catalyst bed. For the microwave experiments, a fiber-optic probe (ATC-FO sensor, Milestones) was inserted at the inlet and outlet of the reactor inside the microwave oven. To avoid bead floating, the catalyst (coated glass beads) bed was fixed to the lower reactor part by glass filters. Constant pressure 
was maintained in the reactor using a syringe valve to avoid solvent boiling and bubble formation in the catalyst bed. The inlet and outlet of the quartz-glass reactor were connected using Swagelok Ultra-Torr (stainless steel, S.S. 316; inner diameter $1.6 \mathrm{~mm}$ ) connections with chemically resistant sealing rings. For the single-mode microwave experiments, a microwave (Fricke und Mallah $\mathrm{GmbH}$ ) setup consisting of a single-mode microwave cavity and operating at a frequency of $2.45 \mathrm{GHz}$ with adjustable power settings up to $2 \mathrm{~kW}$ was utilized (see Supporting Information). Maximum microwave absorption was assured through focusing the resonant microwaves in the cavity by using stub-tuners and short-circuits. The reflected power was measured using a detector diode over the isolator. A LABVIEW interface program was used to control the temperature and power input in the reactor, using OPSENS fiber-optic sensors in the centre of the fixed-bed. The reference case batch experiments were carried out in a mechanically stirred $(500 \mathrm{rpm}) 100 \mathrm{~mL}$ jacketed batch-reactor. Identical setups were used for the batch experiments with oil-bath and microwave heating (see Supporting Information). All reactions were carried out in an argon atmosphere.

\subsection{Product analysis and catalyst characterization}

Product yield analyses. Samples were taken at the outlet of the reactor and diluted with dimethyl sulfoxide- $\mathrm{d}^{6}$ (DMSO-d $\mathrm{d}^{6}$, Cambridge Isotope Laboratories Inc., D 99.9\%) for ${ }^{1} \mathrm{H}$ NMR spectroscopic analyses. ${ }^{1} \mathrm{H}$ NMR data were collected using a Varian 400 NMR spectrometer $(400 \mathrm{MHz})$. The chemical shifts (in $\delta \mathrm{ppm}$ ) were based on TMS (tetramethylsilane) at $27{ }^{\circ} \mathrm{C}$ as internal reference and peak integrations were converted to concentrations by using tetradecane $\left(\mathrm{C}_{14} \mathrm{H}_{30}\right)$ as internal standard. The productivity and product yield were obtained by comparing the reactants (phenoxide and 4-chloropyridine) and the product (4-phenoxypyridine) signals corrected for the internal standard. The ${ }^{1} \mathrm{H}$ NMR of the spectra $\left(\mathrm{CDCl}_{3} ; 8.4-8.6 \mathrm{ppm}\right)$ of the reactants and product after full conversion are shown in the Supporting Information. The ${ }^{1} \mathrm{H}$ NMR assignments for the product in $\delta\left(\mathrm{ppm}, \mathrm{CDCl}_{3}\right)$ 
are: $8.48(\mathrm{~d}, J=4.0 \mathrm{~Hz}, 2 \mathrm{H}), 7.44(\mathrm{t}, J=8.0 \mathrm{~Hz}, 2 \mathrm{H}), 7.29-7.25(\mathrm{~m}, 1 \mathrm{H}), 7.11(\mathrm{~d}, J=8.0 \mathrm{~Hz}$, 2H), $6.85(\mathrm{~d}, J=8.0 \mathrm{~Hz}, 2 \mathrm{H})$. The ${ }^{1} \mathrm{H}$ NMR data was additionally compared with GC-MS data to confirm product formation.

Inductively coupled plasma (ICP) measurements. The losses of catalyst and support were analyzed using inductively coupled plasma measurements, combined with optical emission spectroscopy. A Spectro Ciros ${ }^{C C D}$ spectrometer was used to determine the amounts of copper catalyst and titania and zinc-oxide supports at $1400 \mathrm{~W}$. Sample injection used a nebulizer in a double-pass spray chamber with a sample uptake frequency of $2 \mathrm{~mL} / \mathrm{min}$. For the fixed-bed reactor, the catalyst packing was used as sample material and for the wall-coated reactor, the reactor was dried and ca. $2 \mathrm{~mm}$ of the reactor was cut off for analysis. The samples were treated in $\mathrm{H}_{2} \mathrm{SO}_{4}(5 \mathrm{M})$ for $24 \mathrm{~h}$ before being taken for analysis. In addition, reactions were sampled by collecting an accurate amount of reaction mixture and dissolving it in $\mathrm{H}_{2} \mathrm{SO}_{4}(10$ $\mathrm{mL}, 5 \mathrm{M})$. The resulting aqueous layer was diluted with $10 \mathrm{~mL}$ milli-pore water and separated off by milli-extraction. To avoid an abundance of protonated amide signals, the sample was diluted using an additional $20 \mathrm{~mL}$ volume of milli-pore water. Calibration lines were freshly prepared and inserted prior to the catalyst samples.

X-Ray Photoelectron Spectroscopy (XPS) analyses. XPS was used to analyze the catalyst surface and establish the oxidation state of the copper. Various XPS samples were analyzed either using known amounts (in $\mathrm{mg}$ ) of the wall-coated tubular reactor or by measuring exact quantities of catalyst beads deposited on a carbon holey film in a glove-box $\left(<10 \mathrm{ppm} \mathrm{O}_{2}\right)$. The samples were transported in a closed holder for oxygen-free analysis. XPS data was obtained with a Kratos AXIS Ultra spectrometer equipped with a monochromatic Al Ka X-ray source $(1486.6 \mathrm{eV}$ at $150 \mathrm{~W})$ using a delay-line detector (DLD). Constant pass energies of 160 $\mathrm{eV}$ and $40 \mathrm{eV}$ were applied for survey and region scans, respectively, at a background pressure 
of $2 \times 10^{-9}$ mbar. Based on the spectral intensities of the $\mathrm{Cu}$, conclusions were drawn with respect to losses observed by ICP analysis and the recorded drops in activity.

Electron microscopy analyses. Scanning electron microscopy (SEM) images were obtained using a FEI Quanta series (FEG 3D G2 SEM) with an acceleration voltage of $5 \mathrm{kV}$ and magnifications in the range $5-100 \times 10^{3}$. The images were used to determine the surface morphology and coating thickness of the wall-coating and the catalyst support beads at a lateral resolution of $50 \mathrm{~nm}^{2}$. Simultaneously, surface elemental composition analysis was carried out using energy-dispersive X-ray (EDX) spectroscopy at an image spot size of $50 \mathrm{~nm}^{2}$ and an interaction-volume of $100 \mu \mathrm{m}$ (all EDX spectra are provided in the Supplementary Information). Leaching of the catalytic layer was surveyed by comparing the coating thickness and the $\mathrm{Cu}, \mathrm{Ti}$ and $\mathrm{Zn}$ signals in the EDX spectra. Both the fresh and spent catalysts were analyzed using SEM. The surface structure of spent samples was also investigated to probe the effects of microwave irradiation on morphology changes due to arcing or sintering. The same samples as used for XPS analyses were surveyed and the acquired SEM-EDX results were then compared with the XPS data. In particular the presence of an oxidized or graphitized surface-covering upper layer was compared to either oxidation or the deposition of carbon due to degradation of the solvent as a result of arcing. High resolution transmission electron microscopy (HR-TEM) images, obtained with a FEI Tecnai G2 Sphera electron microscope operating at $200 \mathrm{kV}$ acceleration voltage, were used to examine the particle size and structure of the pre-synthesized $\mathrm{Cu}$ nanoparticles. Nanoparticles supported on the reactor wall and the glass beads were also examined. Samples of fresh and spent catalysts were analyzed. The samples were prepared by scratching the catalyst coating from the reactor wall or by crushing glass beads, respectively, and by suspending the resulting powders in $2 \mathrm{~mL}$ ethanol before coating and drying the solvent onto a 200 mesh molybdenum grid ( $30 \mu \mathrm{L}$ of the suspension). The obtained images provided information on the dispersion of particles on the supports. 


\section{Results and discussion}

In this study two catalytic flow-reactors were investigated, i.e. a fixed-bed reactor based on a $\mathrm{TiO}_{2}$ coating as copper catalyst support and a wall-coated reactor where $\mathrm{ZnO}$ was used as copper catalyst support. Initially, both reactors were tested in a conventionally heated (i.e. oilbath) setup, wherein the catalyst stability and activity were optimized. At process times of up to $12 \mathrm{hr}$ by-product coverage of the surface, oxidation of the catalyst and particle agglomeration were found to be the main causes for catalyst deactivation. The catalyst could partially be regenerated by thermal treatment. At higher on-stream times, leaching played a major role in leading to permanent deactivation of the catalyst.

\subsection{Catalyst design and stability measurements for flow-chemistry}

Zinc oxide wall-coating as Cu support. Figure 4 shows selected SEM images of as-grown ZnO nanowires on the glass reactor surface. Figures $4 \mathrm{a}$ and $4 \mathrm{~b}$ show monodisperse, rod-like crystals $\left(l_{\mathrm{av}}=500 \mathrm{~nm}, \mathrm{~d}_{\mathrm{av}}=20 \mathrm{~nm}\right)$ with a high surface dispersion. However, after $12 \mathrm{~h}$ onstream (Figure 4c) the catalytic wall appeared to be covered with a substance, which, after EDX analysis, was confirmed to be $\mathrm{KCl}$ formed as by-product during the reaction. Treatment with DMA, drying, calcination (at $350{ }^{\circ} \mathrm{C}$ ) and reduction with a hydrogen flow at $200{ }^{\circ} \mathrm{C}$ removed most of this salt from the surface as can be seen in Figure 4d (EDX spectra are provided in the Supporting Information). At higher processing times ( $>24 \mathrm{~h}$ ) ICP analysis confirmed a considerable decrease in the levels of both $\mathrm{Cu}$ catalyst and $\mathrm{ZnO}$ support due to irreversible leaching.

\section{Figure 4}

$\mathrm{ZnO}$ nanowires grown on the internal wall of a tubular glass reactor provided catalyst loadings similar to those for $\mathrm{TiO}_{2}$ on the glass-bead packing, i.e. 1.26 and $1.38 \mathrm{mg}_{\mathrm{Cu}} / \mathrm{mL}_{\text {reactor }}$ for the wall-coated and the fixed-bed reactors, respectively. Although for the wall-coated reactor the 
overall available reaction surface was much lower than for the fixed-bed reactor, similar $\mathrm{Cu}$ loadings on $\mathrm{ZnO}$ and $\mathrm{TiO}_{2}$ were achieved during catalyst deposition onto the supports.

Titania bead-coating as $\mathrm{Cu}$ support. Relatively low absolute amounts of both support $\left(\mathrm{TiO}_{2}\right)$ and catalyst ( $\mathrm{Cu}$ nanoparticles) were deposited on the titania-coated glass beads $\left(\mathrm{d}_{\mathrm{P}} \sim 250 \mu \mathrm{m}\right)$. As described in Section 2.2 the catalyst was prepared using a $\mathrm{TiO}_{2}$ support matrix and the metallic nanoparticles were impregnated after the support was deposited onto silica beads. In this way, the catalyst loading $\left(1.38 \pm 0.15 \mathrm{mg}_{\mathrm{Cu}} / \mathrm{mL}_{\text {reactor }}\right)$ could be accurately controlled in order to obtain a loading that approximated to that of the wall-coated reactor. Figures $5 \mathrm{a}, 5 \mathrm{~b}$ and 5c show the coated beads before and after reaction. The effect of by-product formation, i.e surface coverage by $\mathrm{KCl}$, is clearly visible also in this case. SEM-EDX analysis further confirmed the abundant presence of $\mathrm{KCl}$ salt crystals.

\section{Figure 5}

Copper nanoparticle deposition and stability. In Figure 6, representative TEM images of the nanoparticles are shown for both the fresh and spent $\mathrm{Cu}$ catalysts.

Figure 6

Figures $6 \mathrm{a}$ and $6 \mathrm{c}$ show the fresh and spent catalyst of the fixed-bed $\mathrm{Cu} / \mathrm{TiO}_{2}$ system, respectively. The fresh catalyst clearly demonstrates uniformly dispersed $\mathrm{Cu}$ nanoparticles in the titania matrix. The particle size was found to be $7.6 \pm 0.8 \mathrm{~nm}$ based on measurements for 200 particles in various TEM images. However, after $12 \mathrm{~h}$ on-stream in the fixed-bed reactor, the catalyst particles have significantly agglomerated. Figures $6 \mathrm{~b}$ and $6 \mathrm{~d}$ show TEM images of the fresh and spent wall-coated $\mathrm{Cu} / \mathrm{ZnO}$ catalyst. Clearly, the fresh $\mathrm{Cu} / \mathrm{ZnO}$ wall-coated coated catalyst demonstrates a much higher particle density than does the fresh $\mathrm{Cu} / \mathrm{TiO}_{2}$ catalyst (Figure 6a and 6b). The higher copper loading in the wall-coated reactor was prepared in order to compensate for the lower macroscopic reaction surface in that system. Figure $6 \mathrm{~b}$ 
however shows partial nanoparticle agglomeration already occurring in the fresh catalyst. After $12 \mathrm{~h}$ on-stream the $\mathrm{Cu} / \mathrm{ZnO}$ wall-coated catalyst showed higher nanoparticle agglomerates up to sizes of ca.150 $\mathrm{nm}$ (see Figure $6 \mathrm{~d}$ ).

Catalyst and support leaching. The catalyst and support losses are shown in Figure 7. ICP measurements provided the amounts of $\mathrm{Cu}, \mathrm{Zn}$ (from $\mathrm{ZnO}$ ) and $\mathrm{Ti}$ (from $\mathrm{TiO}_{2}$ ) for samples taken during the total process time.

Figure 7

For the ICP analyses, multiple catalyst samples were taken from the fixed-bed reactor or from the wall-coated reactor as described in Section 2.4. Neither $\mathrm{Cu} / \mathrm{TiO}_{2}$ nor $\mathrm{Cu} / \mathrm{ZnO}$ catalysts leached more than $10 \%$ after $12 \mathrm{~h}$ of run. Figure 7 a shows a significant drop of $c a .30 \mathrm{wt} \%$ of the $\mathrm{Cu}$ signal in the $\mathrm{Cu} / \mathrm{TiO}_{2}$ system after only $24 \mathrm{~h}$ on-stream, whereas $\mathrm{ca} .10 \mathrm{wt} \%$ of the $\mathrm{TiO}_{2}$ support was lost. However, after $48 \mathrm{~h}$ on-stream roughly $60 \mathrm{wt} \%$ of the copper was lost while only $20 \mathrm{wt} \%$ of the Ti had leached. After $72 \mathrm{~h}$ on-stream, both catalyst and support had completely leached from the glass beads. Generally, however, for the $\mathrm{TiO}_{2}$-based fixed-bed reactor, the $\mathrm{Cu}$ nanoparticles appeared to leach prior to the $\mathrm{TiO}_{2}$ support. The opposite was observed for the $\mathrm{ZnO}$-supported system (Figure $7 \mathrm{~b}$ ), where after $48 \mathrm{~h} \mathrm{ca.} 60 \mathrm{wt} \%$ of the $\mathrm{ZnO}$ nanowires were removed while only $40 \mathrm{wt} \%$ of the $\mathrm{Cu}$ nano-catalyst was lost. This observation could only be explained by the fact that although the $\mathrm{ZnO}$ layer was uniformly distributed, the $\mathrm{Cu}$ nanoparticles formed islands that stabilized the $\mathrm{ZnO}$-glass interface. As a result, a much higher $\mathrm{ZnO}$ fraction leached. After $72 \mathrm{~h}$, about $22 \mathrm{wt} \%$ of $\mathrm{ZnO}$ and $36 \mathrm{wt} \%$ of $\mathrm{Cu}$ remained, showing that much less shearing occurred in the wall-coated reactor as compared to the fixed-bed reactor. Overall, at higher process times, adhesion appears to be weak at the $\mathrm{Cu} / \mathrm{TiO}_{2}$-glass interface for the fixed-bed catalyst system and at the $\mathrm{ZnO}$-glass surface for the wall-coated catalyst system. As a result, the subsequent activity experiments 
were only done using processing times lower than $12 \mathrm{~h}$, after which a fresh batch of catalyst was used.

\subsection{Activity experiments}

Initially, the influence of multimode microwave heating and conventional oil-bath heating on catalyst productivity was compared using a continuously stirred batch reactor and a commercial copper catalyst. In the next step, activity measurements on a supported $\mathrm{Cu}$ catalyst were done in an oil-bath using a fixed bed reactor and a wall-coated reactor as examples of flow-type reactors based on titania and zinc oxide support materials, respectively. Finally, microwave flow-experiments were carried out in both a multimode and a single-mode microwave cavity.

\subsubsection{Batch experiments using conventional and microwave heating}

Thermal effects that are caused by microwaves in liquids are straightforwardly stemming from the fact the liquid molecules posses a dipole, which, in an alternating microwave field, would lead to movement, friction and consequently to heating. In the first place the solvent dimethylacetamide and the potassium phenolate possess a dipole-moment and lead to dipolar movement and ionic translation, respectively [68]. Conversely, "non-thermal effects" (e.g. entropic effects) are related to the orientation of the reacting molecules to the electric field and consequently facilitate the reaction pathway. These latter "microwave effects" have been a topic of debate where many authors in the mid-90s argued that the presence of an electric field leads to orientation effects of dipolar molecules to influence the pre-exponential factor [69] or activation energy [70] in the rate coefficient. However, we believe that these "special effects" are difficult, if not impossible, to prove and appeared in many cases to be incorrectly interpreted due to inaccurate temperature measurements $[71,72]$. In case of solids heating the microwave effect could not be attributed to the entropic effect, due to their condensed 
structure, but only to thermal effects stemming both from eddy current loss (in alternating magnetic-field) and magnetic reversal loss (in alternating electric-field) mechanisms in metals [61]. The influence of microwave heating and conductive heating on product yield was investigated at three different reaction temperatures. Figure 8 shows the results of experiments conducted at 110,120 and $140{ }^{\circ} \mathrm{C}$ for both heating methods, where a clear trend can be observed in yields with respect to time. Figure $8 \mathrm{a}$ demonstrates that the use of microwave irradiation instead of oil-bath heating gives an average yield increase of $20 \%$ at $110{ }^{\circ} \mathrm{C}$. At $120^{\circ} \mathrm{C}$ (Figure 8b) the discrepancy between microwave and oil-bath heating is far less than at $110{ }^{\circ} \mathrm{C}$, and it disappears completely at $140{ }^{\circ} \mathrm{C}$ (Figure $8 \mathrm{c}$ ).

Figure 8

The difference in yield between microwave and conductive heating experiments can be attributed to the differential absorption of energy by the catalyst and liquid reaction mixture [54]. Thus, better yields are recorded for microwave heated experiments because higher temperatures are obtained at the locus of the reaction (i.e. catalyst surface) due to selective heating of the catalyst $[59-61,73]$. This trend vanishes at higher reaction temperature probably on account of now being a low temperature difference between the catalyst surface and the bulk liquid [74-77]. Figure 9a shows the temperature time histories for a microwave power of $120 \mathrm{~W}$ and various $\mathrm{Cu}$ catalyst loadings in a batch reactor. The initial heating rates (in ${ }^{\circ} \mathrm{C} / \mathrm{min}$ ) obtained from microwave irradiation appeared to be strongly dependant on the amount of copper catalyst used in a $30 \mathrm{~mL}$ batch reactor, demonstrating an optimum heating rate for low amounts of metallic copper. The decay in heating rate at increased $\mathrm{Cu}$ loadings, shown in Figure $9 b$, is mostly due to arcing effects.

Figure 9

Although it is difficult, if not impossible, to quantify the energy absorption by copper, the heating rates of the liquid in the presence and absence of the catalyst provide an insight into 
the thermal contribution of microwave absorption by the metal [78]. Based on the heating profiles, the microwave heating efficiency [79] has been determined to the work of Stankiewicz et al [80]. For these experiments a jacketed and insulated mechanically stirred batch reactor was used (see Supporting Information), allowing energy losses to the environment to be neglected. Additionally, the microwave heating calculations were based on a cavity-to-reactor power input that ignored losses from the grid to the magnetron. Figure $9 \mathrm{~b}$ shows the heating rate as a function of the amount of catalyst in the reactor and indicates that the use of $20 \mathrm{mg} \mathrm{Cu}$ catalyst increased the heating rate from 67 to $87^{\circ} \mathrm{C} / \mathrm{min}$ relative to the heating rate obtained in the absence of catalyst. However, the heating rate stabilizes at higher catalyst loadings, reaching ca. $71{ }^{\circ} \mathrm{C} / \mathrm{min}$ for $100 \mathrm{mg}$ catalyst. While heating efficiency decayed, an almost linear increase in the frequency of arcing was observed, indicating a breakdown in microwave energy accumulation in the catalyst particles, but not necessarily an increase in thermal energy or conversion [56]. This also explains why in Figure 8 better yields were observed for microwave heating at lower powers than for oil-bath heating; microwave energy heated the catalyst surface at lower powers (without arcing), leading to higher yields than expected from the measured temperatures in the bulk liquid.

\subsubsection{Batch versus continuous reactors with oil-bath heating}

Heterogeneously catalyzed flow-reactors have been developed with the intention both of increasing process productivity and ease of catalyst regeneration in comparison to what is achievable with conventional batch-type reactors. For this reason, different flow parameters have received special attention in this study. Firstly, the performance of the catalyst carrier ( $\mathrm{ZnO}$ wall coating versus $\mathrm{TiO}_{2}$ fixed-bed coating) in a tubular reactor was investigated to improve the productivity per unit catalyst mass as compared to traditional batch reactors for fine-chemical operations. Secondly, the influence of mixing was investigated by comparing a 
fixed-bed (disturbed-flow) with a wall-coated (laminar-flow) continuous reactor. The results for these continuous systems were also compared with those obtained using a mechanically stirred and jacket-heated batch reactor, as described in the previous section. Figure 10 shows the product yields as a function of residence time at $130{ }^{\circ} \mathrm{C}$ for a continuous fixed-bed, wallcoated and slurry-type continuous reactor in comparison with those of a slurry-type batch reactor containing metallic copper powder as catalyst.

Figure 10

Compared to the $58 \%( \pm 2)$ yield obtained after $30 \mathrm{~min}$ using the batch reactor, the yield stagnates at ca. $18 \%$ after $10 \mathrm{~min}$ (at flowrates of $5-80 \mathrm{~mL} / \mathrm{h}$ ) for both the fixed-bed and the wall-coated batch-loop flow-reactors. In these cases the highest turnovers are achieved in the first two cycles, while further recycling of the reaction mixture did not lead to a significant yield increase. This flattening of the yield, after only the second cycle, was clearly caused by catalyst deactivation due to oxidation and coke deposition. For these reactor types, catalyst deactivation and regeneration were evaluated through variation of the pre-treatment and posttreatment methods.

\subsubsection{Fixed-bed and wall-coated continuous reactors with oil-bath heating}

$\mathrm{Cu} / \mathrm{TiO}_{2}$ fixed-bed flow reactor. In most heterogeneous catalyst systems, the conversion drops noticeably when the catalyst surface is subjected to a fluid flow that leads to catalyst oxidation or deactivation due to coke deposition. Catalyst leaching also results from the high shear forces applied to the catalyst surface by the flow. Moreover, catalyst deactivation by surface oxidation occurs when the chemical components possess oxidative properties. This causes physicochemical changes to the active metal and leads to $\mathrm{Cu}^{\mathrm{I}}$ or $\mathrm{Cu}^{\mathrm{II}}$ species which have an increased solubility in the amide-containing solvent, facilitating catalyst leaching from the support. To avoid leaching, catalyst regeneration is usually performed by slow heating (to 
$>200{ }^{\circ} \mathrm{C}$ ) until all surface contaminants have been removed through evaporation and, finally, by combustion of adsorbed organic compounds. Parameters such as calcinations temperature and time have to be optimized for regeneration of the deactivated catalyst. The effect of a calcination procedure (at $350{ }^{\circ} \mathrm{C}$ for $12 \mathrm{~h}$ ) on the product yield was investigated for a freshcatalyst with reference to a non-calcined fresh catalyst sample. Figure 11 demonstrates clearly enhanced yields and the necessity of catalyst calcination at $350{ }^{\circ} \mathrm{C}$.

\section{Figure 11}

These results show clearly that catalyst stability was improved by an optimized calcination during catalyst synthesis. Enhanced catalyst activity was found to result in a yield increase of roughly $10 \%$ after $30 \mathrm{~min}$ on-stream (see Figure 11 ). Lastly spent catalyst (on-stream for ca. $8 \mathrm{~h}$ ) was regenerated at $350{ }^{\circ} \mathrm{C}$ and its performance was compared with that of fresh catalyst calcined at at $350{ }^{\circ} \mathrm{C}$ (Figure 12). The regenerated catalyst now showed a yield drop of $c a .8 \%$ in comparison to the fresh catalyst. This shows that the high-temperature calcination was necessary to retain catalyst activity in the flow-through reactor. However, at longer reaction times catalyst regeneration by calcination permitted only the partial retention of activity. Therefore, the main limitation in processing this fixed-bed reactor would be catalyst deactivation and leaching.

\section{Figure 12}

Cu/ZnO wall-coated flow-reactor. Yields obtained using the $\mathrm{ZnO}$ wall-coated reactor were comparable to those seen with the fixed-bed type reactor up to 60-min operation (Figure 13). More importantly, the $\mathrm{ZnO}$-supported catalyst appears to retain its activity for operation times longer than those for the $\mathrm{TiO}_{2}$-supported fixed-bed systems, leading to yields up to $40 \%( \pm 2$ \%) after ca. 90 min on-stream.

Figure 13 
Similar to the fixed-bed system (Figure 12), regenerated wall-coated catalyst demonstrated a slight drop in activity comparable to the analogous fresh catalyst. A steady state product yield of $30 \%( \pm 3 \%)$ instead of $39 \%( \pm 2 \%)$ was maintained until 124 min (Figure 13). Catalyst regeneration could also be improved by extending the $350{ }^{\circ} \mathrm{C}$ calcination step to $24 \mathrm{~h}$. This led to a yield of $61 \%( \pm 1 \%)$ after 71 min using a fresh catalyst (Figure $13, \Delta)$ and of $57 \%( \pm 1 \%)$ after a further $71 \mathrm{~min}$ if the spent catalyst was regenerated by calcination at $350{ }^{\circ} \mathrm{C}$ for $24 \mathrm{~h}$ (Figure 13, ○). These values represent yield increases of ca. $50 \%$ with respect to those obtained when fresh and spent catalysts were calcined for only $12 \mathrm{~h}$. Table 1 compares the productivities of fresh and regenerated catalysts for both reactor types.

\section{Table 1}

Although the yields obtained from the $\mathrm{Cu} / \mathrm{ZnO}$ wall-coated catalyst was slightly higher than the $\mathrm{Cu} / \mathrm{TiO}_{2}$ fixed-bed catalyst, the reactor productivities, however, showed higher performance for the latter. While the catalyst loading per volume reactor was comparable for both reactors, unequal reactor to liquid volume fractions $\left(V_{L} / V_{R}\right)$ led to different overall reactor productivities. For both reactors, however, a productivity decrease around $30 \%$ was observed for a total time on process of $12 \mathrm{hr}$.

Calcination of both the $\mathrm{Cu} / \mathrm{TiO}_{2}$ fixed-bed and $\mathrm{Cu} / \mathrm{ZnO}$ wall-coated reactors at $200{ }^{\circ} \mathrm{C}$ resulted in an obvious drop in yield, although a $24 \mathrm{~h}$ calcination treatment at $200{ }^{\circ} \mathrm{C}$ led to stable catalyst activities for four consecutive runs with a residence time of $70 \mathrm{~min}$. However, much higher yields were obtained for the latter (Figure 14).

\section{Figure 14}

Figures 12,13 and 14 show that the sustainability of both $\mathrm{Cu} / \mathrm{ZnO}$ and $\mathrm{Cu} / \mathrm{TiO}_{2}$ catalysts are mainly governed by the duration, rather than the temperature, of the calcination procedure. The first part of the regeneration process $\left(80{ }^{\circ} \mathrm{C}, 10 \mathrm{mbar}\right)$ was mainly done to evaporate all 
components of the reaction mixture. In a second step, residual coke was burned (at $350{ }^{\circ} \mathrm{C}$ ) in an air-flow $\left(22 \% \mathrm{O}_{2}\right.$ in $\mathrm{N}_{2}$ ). In the final step, a stable catalyst-support matrix was achieved by a slow cooling trajectory (see the Supporting Information for a detailed scheme).

\subsection{Multimode versus single-mode microwave heating in continuous processesing}

Although the $\mathrm{Cu} / \mathrm{ZnO}$-based wall-coated reactor showed a better catalyst performance in terms of yields, its application in microwave heating may still be limited of their being large temperature gradients between the centre of the reactor and the wall. In such a case, a fixedbed reactor would provide a more uniform heating profile due to internal mixing and the presence of highly dispersed copper microwave absorber. Therefore, a fixed-bed reactor was tested in both a single-mode and in a multimode cavity microwave-heated flow system. The reactor inlet and outlet were slightly modified to fit the microwave cavity dimensions. Figure 15a shows the temperature-time and power-time histories for the use of multimode microwave cavity. In Figure $15 \mathrm{~b}$ temperature-time and power-time histories for the single-mode microwave cavity setup are given. The microwave power requirements for a multimode microwave experiment were found to be 10 times more $(300 \mathrm{~W})$ due to the non-uniform and low-density microwave irradiation in comparison to the monomode microwave experiment $(30 \mathrm{~W})$. Although the single-mode microwaves showed slightly larger temperature and power fluctuations, these equated to less than $5{ }^{\circ} \mathrm{C}$.

Figure 15

Figure 16a shows that for the $\mathrm{Cu} / \mathrm{TiO}_{2} / \mathrm{SiO}_{2}$ fixed-bed catalyst a threefold yield increase resulted when single-mode microwave irradiation was utilized. This could be explained by the fact that in a multimode cavity the microwaves are non-uniformly distributed. As a result of non-uniform "microwave distribution" in a multimode microwave oven, the reactor is 
irregularly subjected to high-density and low-density energy zones which result in "coldspots" and "hot-spots" in the reactor tube. The catalyst deactivation and product yield decrease in multimode microwaves are mainly caused by "the hotspots", which lead to arcing and consequently burning of the reactants resulting in coke formation onto the catalyst. This explains the reduced yields in a multimode microwave cavity in flow-reactors as compared to reaction in single-mode microwave cavities [81]. Single-mode microwaves, on the other hand, are uniformly distributed in the cavity and cause the entire reactor to be irradiated with an equal microwave density. As a consequence, in a single-mode microwave cavity far less energy input is required to attain the reaction temperature as compared to multimode microwave cavities leading to sufficient energy to heat the catalyst. In this way destructive arcing and reactants decomposition is avoided. This effect has been confirmed recently by Chen et al. who showed that at excessive microwave powers subjected to diamagnetic and paramagnetic metallic particles leads to complete discharges and destructive arcing [75]. Conversely, at lower microwave power input the particles would heat up very fast but would not lead to arcing and, dependent on the type of metal and the reaction medium, leads to desirable catalyst temperatures. The use of lower power in case of multimode microwaves could not attain the desired reaction temperatures, whilst at higher powers $(>300 \mathrm{~W})$ arcing limits the productivity. Also clearly visible is the yield flattening at around $35 \%$ yield, which, as discussed in section 3.2.3, was mainly due to oxidation and poisoning of the catalyst.

\section{Figure 16}

Previously, it has been reported that the $\mathrm{Cu}$ catalyst could be protected against oxidation and that leaching could be minimized by adding $50 \mathrm{wt} \%$ of $\mathrm{Zn}$ to the catalyst as a sacrificial reducing agent $[53,82,83]$. Consistent with this view, Figure $16 \mathrm{~b}$ shows that a considerable yield increase was achieved when a CuZn-based heterogeneous catalyst was used in the fixed- 
bed reactor. Although for low residence times $(<60 \mathrm{~min})$ no major improvement was obtained, at longer residence times two-fold yield increases were achieved for both singlemode and multimode systems. Comparing Figure 16b with Figure 11 signifies that the main reason for this improvement is indeed that, regardless of the heating method, catalyst deactivation is retarded when a CuZn catalyst is used. Figure 15 demonstrates that the energy efficiency achieved using the single-mode microwave cavity of the Fricke-Mallah instrument reached $82 \%( \pm 4 \%)$ with an average power input of $16 \mathrm{~W}$, while the multimode cavity system could at best be operated with an energy efficiency of only $8.2 \%( \pm 0.8 \%$ ) (following notes [73] and [74]). Use of the single-mode microwave cavity for a Cu-based heterogeneous catalyst gave a yield of $33 \%( \pm 1 \%)$ for a residence time of ca. 120 min with a productivity of $130 \mathrm{~kg}_{\text {prod }} /\left(\mathrm{m}_{\mathrm{R}}^{3} \cdot \mathrm{h}\right)$. Only $37 \mathrm{~kg}_{\text {prod }} /\left(\mathrm{m}_{\mathrm{R}}{ }^{3} \cdot \mathrm{h}\right)$ was obtained in the case of the multimode cavity system. However, a highest yield of $62 \%( \pm 3 \%)$ and a productivity of $172 \mathrm{~kg}_{\mathrm{prod}} /\left(\mathrm{m}_{\mathrm{R}}{ }^{3} \cdot \mathrm{h}\right)$ could be achieved using a CuZn-based catalyst in combination with single-mode microwave heating. These high space-time yields have, to the best of our knowledge, not yet been reported for Ullmann-type coupling reactions using flow-processing.

\section{Conclusions}

In this work two flow milli-reactors for microwave-assisted Ullmann-type $\mathrm{C}-\mathrm{O}$ coupling reaction are presented. A wall-coated ( $\mathrm{ZnO}$ support) and a fixed-bed $\left(\mathrm{TiO}_{2}\right.$ support) millireactor were developed and impregnated with $\mathrm{Cu}$ nanoparticles as active catalyst. These catalytic reactors allowed feasible catalyst regeneration by repetition of oxidation and reduction cycles and shows novelty, in particular, as it is able to deal with development of well-defined supported catalysts. Copper catalyst leaching for both reactors appeared to be only significant after $24 \mathrm{~h}$ on-stream and this could partially be avoided by thermal treatment of the reactor after each cycle. Up to $60 \%$ yield could be obtained using the $\mathrm{Cu} / \mathrm{ZnO}$ wall-coated reactor for two 
consecutive runs without there being a significant activity drop if a thermal pre-treatment of the reactor $\left(350{ }^{\circ} \mathrm{C}\right.$ for $\left.24 \mathrm{~h}\right)$ was undertaken prior to testing. The $\mathrm{Cu} / \mathrm{TiO}_{2}$ fixed-bed reactor showed lower yields due to catalyst leaching, however reactor productivities of up to 55 $\mathrm{kg}_{\text {prod }} /\left(\mathrm{m}_{\mathrm{R}}^{3} \cdot \mathrm{h}\right)$ suggested a better performance than the $\mathrm{Cu} / \mathrm{ZnO}$ wall-coated reactor. Microwaves were therefore applied to the $\mathrm{Cu} / \mathrm{TiO}_{2}$ fixed-bed reactor as an alternative energy source for liquid and selective catalyst heating. The use of high density single-mode microwaves showed a three-fold yield increase in the $\mathrm{Cu} / \mathrm{TiO}_{2}$ fixed-bed reactor relative to the use of multimode microwaves. Furthermore, the use of metallic copper in the microwave cavities appeared to be only advantageous at low microwave powers and catalyst loadings; at higher powers and catalyst loadings arcing was observed, leading to rapid catalyst deactivation and inefficient heating. A linear relation between the arcing frequency and the catalyst loading was found. It was demonstrated that yields obtained using microwave heating at $140 \mathrm{~W}$ were almost $30 \%$ higher than those achieved using oil-bath heating, whereas no significant yield increase was observed at $300 \mathrm{~W}$. More important was the use of $\mathrm{CuZn} / \mathrm{TiO}_{2}$ based catalyst, where the $\mathrm{Zn}$ acted as a sacrificial anode against $\mathrm{Cu}$ oxidation. In this case a three-fold yield increase could be demonstrated in highly dense single-mode microwave cavity which, to the best of our knowledge, resulted to not yet reported productivity of up to $172 \mathrm{~kg}_{\mathrm{prod}}\left(\mathrm{m}_{\mathrm{R}}{ }^{3} \cdot \mathrm{hr}\right)$ for microwave-assisted flow synthesis in the Ullmann $\mathrm{C}-\mathrm{O}$ coupling.

\section{Acknowledgement}

The authors would like to thank the Dutch Technology Foundation STW (project MEMFiCS GSPT-07974), DSM Research, Friesland Campina, LioniX, Institut Für Mikrotechnik Mainz (IMM, Germany), Milestone s.r.l. (Italy) as well as The Royal Society (International Joint 
Project 2008/R4 “'Smart Structured Multiphase Reactors for Process Intensification’) for financial and in-kind support.

Supporting Information Available: Supplementary data (xxxxxxxxx description of data

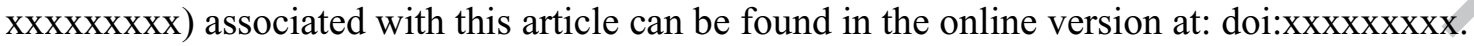

[References and Notes]

[1] T. Brodmann, P. Koos, A. Metzger, P. Knochel, S.V. Ley, Continuous Preparation of Arylmagnesium Reagents in Flow with Inline IR Monitoring, Organic Process Research \& Development, (2011).

[2] T. Fukuyama, M.T. Rahman, I. Ryu, I.R. Baxendale, J.J. Hayward, S. Lanners, S.V. Ley, C.D. Smith, B. Ahmed-Omer, T. Wirth, V. Hessel, P. Löb, H. Löwe, K. Koch, F.P.J.T. Rutjes, J.C.M. van Hest, Organic Chemistry in Microreactors, in: Microreactors in Organic Synthesis and Catalysis, Wiley-VCH Verlag GmbH \& Co. KGaA, 2008, pp. 59-209.

[3] T. Illg, P. Loeb, V. Hessel, Flow chemistry using milli- and microstructured reactors-From conventional to novel process windows, Bioorganic \& Medicinal Chemistry, 18 (2010) 3707-3719.

[4] K. Jähnisch, V. Hessel, H. Löwe, M. Baerns, Chemistry in Microstructured Reactors, Angewandte Chemie International Edition, 43 (2004) 406-446.

[5] G.S. Kumar, B. Pieber, K.R. Reddy, C.O. Kappe, Copper-Catalyzed Formation of C-O Bonds by Direct $\alpha$-C$\mathrm{H}$ Bond Activation of Ethers Using Stoichiometric Amounts of Peroxide in Batch and Continuous-Flow Formats, Chemistry - A European Journal, 18 (2012) 6124-6128.

[6] N.G. Anderson, Using Continuous Processes to Increase Production, Organic Process Research \& Development, 5 (2012) 852-869.

[7] V. Hessel, P. Löb, H. Löwe, Industrial Microreactor Process Development up to Production, in: Microreactors in Organic Synthesis and Catalysis, Wiley-VCH Verlag GmbH \& Co. KGaA, 2008, pp. 240.

[8] C.O. Kappe, D. Dallinger, S.S. Murphree, Practical Microwave Synthesis for Organic Chemists, Wiley-VCH, Weinheim, 1 (2009).

[9] T. Wirth, Microreactors in Organic Synthesis and Catalysis, in: WILEY-VCH, 2008.

[10] V. Hessel, A. Renken, J.C. Schouten, J. Yoshida, Micro Process Engineering: A Comprehensive Handbook, in, Wiley-VCH, 2009

[11] J.D. Moseley, C.O. Kappe, A critical assessment of the greenness and energy efficiency of microwaveassisted organic synthesis, Green Chemistry, 13 (2011) 794-806.

[12] V. Hessel, Novel Process Windows - Gate to Maximizing Process Intensification via Flow Chemistry, Chemical Engineering \& Technology, 32 (2009) 1655-1681.

[13] M. Hempel, Novel Process Windows - A Contribution to More Sustainable Chemistry?, Chemical Engineering \& Technology, 32 (2009) 1651-1654.

[14] V. Hessel, D. Kralisch, U. Krtschil, Sustainability through green processing - novel process windows intensify micro and milli process technologies, Energy \& Environmental Science, 1 (2008) 467-478.

[15] A. Stankiewicz, On the Applications of Alternative Energy Forms and Transfer Mechanisms in Microprocessing Systems, Industrial \& Engineering Chemistry Research, 46 (2007) 4232-4235.

[16] C.O. Kappe, Aqueous Microwave-Assisted Chemistry. Edited by Vivek Polshettiwar and Rajender S. Varma, ChemSusChem, 3 (2010) 1085-1085.

[17] M.H.C.L. Dressen, B.H.P. van de Kruijs, J. Meuldijk, J.A.J.M. Vekemans, L.A. Hulshof, Flow Processing of Microwave-Assisted (Heterogeneous) Organic Reactions, Organic Process Research \& Development, 14 (2010) 351-361.

[18] J.D. Moseley, Microwave synthesis in process chemistry. Method, scale and scope Chimica Oggi, 27 (2009) 6-10.

[19] T.N. Glasnov, C.O. Kappe, Microwave-Assisted Synthesis under Continuous-Flow Conditions, Macromolecular Rapid Communications, 28 (2007) 395-410.

[20] G. Shore, S. Morin, M.G. Organ, Catalysis in Capillaries by Pd Thin Films Using Microwave-Assisted Continuous-Flow Organic Synthesis (MACOS), Angewandte Chemie International Edition, 45 (2006) 27612766. 
[21] D. Dallinger, H.r. Lehmann, J.D. Moseley, A. Stadler, C.O. Kappe, Scale-Up of Microwave-Assisted Reactions in a Multimode Bench-Top Reactor, Organic Process Research \& Development, 15 (2011) 841-854.

[22] V. Hessel, B. Cortese, M.H.J.M. de Croon, Novel process windows - Concept, proposition and evaluation methodology, and intensified superheated processing, Chemical Engineering Science, 66 (2011) 1426-1448.

[23] F. Benaskar, V. Hessel, U. Krtschil, P. Löb, A. Stark, Intensification of the Capillary-Based Kolbe-Schmitt

Synthesis from Resorcinol by Reactive Ionic Liquids, Microwave Heating, or a Combination Thereof, Organic Process Research \& Development, 13 (2009) 970-982.

[24] G. Shore, W.-J. Yoo, C.-J. Li, M.G. Organ, Propargyl Amine Synthesis Catalysed by Gold and Copper Thin Films by Using Microwave-Assisted Continuous-Flow Organic Synthesis (MACOS), Chemistry - A European Journal, 16 (2010) 126-133.

[25] E. Comer, M.G. Organ, A Microreactor for Microwave-Assisted Capillary (Continuous Flow) Organic Synthesis, Journal of the American Chemical Society, 127 (2005) 8160-8167.

[26] G. Cravotto, M. Beggiato, A. Penoni, G. Palmisano, S. Tollari, J.-M. Lévêque, W. Bonrath, High-intensity ultrasound and microwave, alone or combined, promote $\mathrm{Pd} / \mathrm{C}$-catalyzed aryl-aryl couplings, Tetrahedron Letters, 46 (2005) 2267-2271.

[27] F. Bergamelli, M. Iannelli, J.A. Marafie, J.D.A. Moseley, A Commercial Continuous Flow Microwave Reactor Evaluated for Scale-Up, Organic Process Research \& Development, 14 (2010) 926-930.

[28] J.D. Moseley, E.K. Woodman, Scaling-Out Pharmaceutical Reactions in an Automated Stop-Flow Microwave Reactor, Organic Process Research \& Development, 12 (2008) 967-981.

[29] J.D. Moseley, P. Lenden, M. Lockwood, K. Ruda, J.-P. Sherlock, A.D. Thomson, J.P. Gilday, A Comparison of Commercial Microwave Reactors for Scale-Up within Process Chemistry, Organic Process Research \& Development, 12 (2007) 30-40.

[30] P. Öhrngren, A. Fardost, F. Russo, J.-S. Schanche, M. Fagrell, M. Larhed, Evaluation of a Nonresonant Microwave Applicator for Continuous-Flow Chemistry Applications, Organic Process Research \& Development, 5 (2012) 1053-1063.

[31] N.G. Patil, A.I.G. Hermans, F. Benaskar, J. Meuldijk, L. A. Hulshof, V. Hessel, J.C. Schouten, E.V. Rebrov, Energy efficient and controlled flow processing under microwave heating by using a millireactor-heat exchanger, AIChE Journal, (2011) online.

[32] U. Schön, J. Messinger, S. Eichner, A. Kirschning, Comparison of monomode and multimode microwave equipment in Suzuki-Miyaura reactions--en route to high throughput parallel synthesis under microwave conditions, Tetrahedron Letters, 49 (2008) 3204-3207.

[33] C.O. Kappe, A. Stadler, Microwave Theory, in: Microwaves in Organic and Medicinal Chemistry, WileyVCH Verlag GmbH \& Co. KGaA, 2006, pp. 9-28.

[34] C.O. Kappe, A. Stadler, Introduction: Microwave Synthesis in Perspective, in: Microwaves in Organic and Medicinal Chemistry, Wiley-VCH Verlag GmbH \& Co. KGaA, 2006, pp. 1-7.

[35] M. Gupta, E.W. Wai Leong, Index, in: Microwaves and Metals, John Wiley \& Sons (Asia) Pte Ltd, 2007, pp. 223-228.

[36] K. Olofsson, A. Hallberg, M. Larhed, Transition Metal Catalysis and Microwave Flash Heating in Organic Chemistry, in: Microwaves in Organic Synthesis, Wiley-VCH Verlag GmbH \& Co. KGaA, 2004, pp. 379-403.

[37] A.R. Muci, S.L. Buchwald, Practical palladium catalysts for C-N and C-O bond formation, Cross-Coupling Reactions, 219 (2002) 131-209.

[38] A.F. Littke, G.C. Fu, Palladium-catalyzed coupling reactions of aryl chlorides, Angewandte ChemieInternational Edition, 41 (2002) 4176-4211.

[39] J. Hassan, M. Sevignon, C. Gozzi, E. Schulz, M. Lemaire, Aryl-aryl bond formation one century after the discovery of the Ullmann reaction, Chem. Rev., 102 (2002) 1359-1469.

[40] J.P. Finet, A.Y. Fedorov, S. Combes, G. Boyer, Recent advances in Ullmann reaction: Copper(II) diacetate catalysed N-, O- and S-arylation involving polycoordinate heteroatomic derivatives, Current Organic Chemistry, 6 (2002) 597-626.

[41] B.H. Yang, S.L. Buchwald, Palladium-catalyzed amination of aryl halides and sulfonates, Journal of Organometallic Chemistry, 576 (1999) 125-146.

[42] J.F. Hartwig, Transition metal catalyzed synthesis of arylamines and aryl ethers from aryl halides and triflates: Scope and mechanism, Angewandte Chemie-International Edition, 37 (1998) 2047-2067.

[43] F. Benaskar, A. Ben-Abdelmoumen, N.G. Patil, E.V. Rebrov, J. Meuldijk, L.A. Hulshof, V. Hessel, U. Krtschil, J.C. Schouten, Cost Analysis for a Continuously Operated Fine Chemicals Production Plant at 10 $\mathrm{Kg} /$ Day Using a Combination of Microprocessing and Microwave Heating, Journal of Flow Chemistry, 1 (2011) 74-89. 
[44] F. Monnier, M. Taillefer, Catalytic C-C, C-N, and C-O Ullmann-Type Coupling Reactions, Angewandte Chemie International Edition, 48 (2009) 6954-6971.

[45] J.Y. Kim, J.C. Park, A. Kim, A.Y. Kim, H.J. Lee, H. Song, K.H. Park, Cu2O Nanocube-Catalyzed CrossCoupling of Aryl Halides with Phenols via Ullmann Coupling, Eur. J. Inorg. Chem., (2009) 4219-4223.

[46] J. Niu, H. Zhou, Z. Li, J. Xu, S. Hu, An Efficient Ullmann-Type C-O Bond Formation Catalyzed by an AirStable Copper(I)-Bipyridyl Complex, Journal of Organic Chemistry, 73 (2008) 7814-7817.

[47] F. Monnier, M. Taillefer, Catalytic C-C, C-N, and C-O Ullmann-Type Coupling Reactions: Copper Makes a Difference, Angewandte Chemie International Edition, 47 (2008) 3096-3099.

[48] G. Evano, N. Blanchard, M. Toumi, Copper-Mediated Coupling Reactions and Their Applications in Natural Products and Designed Biomolecules Synthesis, Chemical Reviews, 108 (2008) 3054-3131.

[49] M. Kidwai, N.K. Mishra, V. Bansal, A. Kumar, S. Mozumdar, Cu-nanoparticle catalyzed O-arylation of phenols with aryl halides via Ullmann coupling, Tetrahedron Letters, 48 (2007) 8883-8887.

[50] K. Kunz, U. Scholz, D. Ganzer, Renaissance of Ullmann and Goldberg Reactions - Progress in Copper Catalyzed C-N-, C-O- and C-S-Coupling, Synlett, 2003 (2003) 2428-2439.

[51] M. Taillefer, H.-J. Cristau, P.P. Cellier, J.-F. Spindler, A. Ouali, Fr 2840303-WO 03101966 (Pr. Nb. Fr 2002 06717), (2002).

[52] V. Engels, F. Benaskar, N. Patil, E.V. Rebrov, V. Hessel, L.A. Hulshof, D.A. Jefferson, J.A.J.M. Vekemans, S. Karwal, J.C. Schouten, A.E.H. Wheatley, Cu-Based Nanoalloys in the Base-Free Ullmann Heterocyle-Aryl Ether Synthesis, Organic Process Research \& Development, 14 (2010) 644-649.

[53] F. Benaskar, V. Engels, E.V. Rebrov, N.G. Patil, J. Meuldijk, P.C. Thüne, P.C.M.M. Magusin, B. Mezari, V. Hessel, L.A. Hulshof, E.J.M. Hensen, A.E.H. Wheatley, J.C. Schouten, New Cu-Based Catalysts Supported on TiO2 Films for Ullmann SNAr-Type C O Coupling Reactions, Chemistry - A European Journal, 18 (2012) $1800-1810$

[54] A. Mondal, D. Agrawal, A. Upadhyaya, Microwave Heating of Pure Copper Powder with Varying Particle Size and Porosity, International Microwave Power Institute, 43 (2009) 5-10.

[55] X. Zhang, D.O. Hayward, D.M.P. Mingos, Effects of Microwave Dielectric Heating on Heterogeneous Catalysis, Catalysis Letters, 88 (2003) 33-38.

[56] A.G. Whittaker, D.M.P. Mingos, Synthetic reactions using metal powders under microwave irradiation, Journal of the Chemical Society, Dalton Transactions, (2002) 3967-3970.

[57] G. Bond, R.B. Moyes, D.A. Whan, Recent applications of microwave heating in catalysis, Catalysis Today, 17 (1993) 427-437.

[58] W.L. Perry, D.W. Cooke, J.D. Katz, A.K. Datye, On the possibility of a significant temperature gradient in supported metal catalysts subjected to microwave heating, Catalysis Letters, 47 (1997) 1-4.

[59] D. Walton, H. Boehnel, D.J. Dunlop, Response of magnetic nanoparticles to microwaves, Applied Physics Letters, 85 (2004) 5367-5369.

[60] D. Walton, Resetting the magnetization of assemblies of nanoparticles with microwaves, Journal of Applied Physics, 95 (2004) 5247-5248.

[61] V.D. Buchelnikov, D.V. Louzguine-Luzgin, G. Xie, S. Li, N. Yoshikawa, M. Sato, A.P. Anzulevich, I.V. Bychkov, A. Inoue, Heating of metallic powders by microwaves: Experiment and theory, Journal of Applied Physics, 104 (2008) 113505.

[62] A.G. Whittaker, D.M.P. Mingos, Arcing and other microwave characteristics of metal powders in liquid systems, Journal of the Chemical Society, Dalton Transactions, (2000) 1521-1526.

[63] J.R. Thomas, Particle size effect in microwave-enhanced catalysis, Catalysis Letters, 49 (1997) 137-141.

[64] V. Engels, F. Benaskar, D.A. Jefferson, B.F.G. Johnson, A.E.H. Wheatley, Nanoparticulate copper - routes towards oxidative stability, Dalton T, 39 (2010) 6496-6502.

[65] F. Benaskar, V. Engels, N. Patil, E.V. Rebrov, J. Meuldijk, V. Hessel, L.A. Hulshof, D.A. Jefferson, J.C. Schouten, A.E.H. Wheatley, Copper(0) in the Ullmann heterocycle-aryl ether synthesis of 4-phenoxypyridine using multimode microwave heating, Tetrahedron Letters, 51 (2010) 248-251.

[66] F. Benaskar, V. Engels, N. Patil, E.V. Rebrov, J. Meuldijk, V. Hessel, L.A. Hulshof, D.A. Jefferson, J.C. Schouten, A.E.H. Wheatley, Copper(0) in the Ullmann heterocycle-aryl ether synthesis of 4-phenoxypyridine using multimode microwave heating, Tetrahedron Lett., 51 (2010) 248-251.

[67] G. Piperata, J.M. Meichtry, M.I. Litter, Photocatalytic reactions over $\mathrm{TiO}_{2}$ supported on porcelain spheres, in: F. Galembeck (Ed.) Progress in Colloid and Polymer Science - Surface and colloid science, Springer, Berlin, 2004, pp. 303-308.

[68] C.O. Kappe, A. Stadler, Chapter 2. Microwave Theory, in: Microwaves in Organic and Medicinal Chemistry, Wiley-VCH Verlag GmbH \& Co. KGaA, 2006, pp. 9-28.

[69] J. Jacob, L.H.L. Chia, F.Y.C. Boey, Thermal and non-thermal interaction of microwave radiation with materials, Journal of Materials Science, 30 (1995) 5321-5327.

[70] D.A. Lewis, J.D. Summers, T.C. Ward, J.E. McGrath, Accelerated imidization reactions using microwave radiation, Journal of Polymer Science Part A: Polymer Chemistry, 30 (1992) 1647-1653. 
[71] M.H.C.L. Dressen, B.H.P. van de Kruijs, J. Meuldijk, J.A.J.M. Vekemans, L.A. Hulshof, Vanishing Microwave Effects: Influence of Heterogeneity, Organic Process Research \& Development, 5 (2007) 865-869.

[72] C.O. Kappe, Controlled Microwave Heating in Modern Organic Synthesis, Angewandte Chemie International Edition, 43 (2004) 6250-6284.

[73] V.F. Meshcheryakov, Y.K. Fetisov, A.A. Stashkevich, G. Viau, Magnetic and microwave properties of nanocomposite films on the basis of Fe--Co--Ni particles of various shapes, Journal of Applied Physics, 104 (2008) 063910.

[74] D. Stuerga, M. Delmotte, Wave-Material Interactions, Microwave Technology and Equipment, in: Microwaves in Organic Synthesis, Wiley-VCH Verlag GmbH \& Co. KGaA, 2004, pp. 1-33.

[75] W. Chen, B. Gutmann, C.O. Kappe, Characterization of Microwave-Induced Electric Discharge Phenomena in Metal-Solvent Mixtures, ChemistryOpen, 1 (2012) 39-48.

[76] A.G. Whittaker, D.M.P. Mingos, Microwave-assisted solid-state reactions involving metal powders, Journal of the Chemical Society, Dalton Transactions, (1995) 2073-2079.

[77] N.G. Patil, E.V. Rebrov, K. Eränen, F. Benaskar, J. Meuldijk, J.-P. Mikkola, V. Hessel, L.A. Hulshof, D.Y. Murzin, J.C. Schouten, Effect of the load size on the efficiency of microwave heating under stop-flow and continuous-flow conditions, Journal of the Microwave Power and Electromagnetic Energy, 46 (2012) 83-92.

[78] The presence of copper also shows heating rates higher compared to those in the absence of copper, which indicates an additional solids absorption term in the overall microwave energy absorption. The following equation has been applied to demonstrate a global energy balance: $\mathrm{Q}(\mathrm{MW})=\mathrm{Q}$ (liquid) $+\mathrm{Q}($ solid $)=$ $\left\{\mathrm{m}^{*} \mathrm{Cp} \mathrm{p}^{*}(\Delta \mathrm{T} / \Delta \mathrm{t})\right\}(\mathrm{DMA})+\mathrm{Q}(\mathrm{Cu})$. Where $\mathrm{Q}(\mathrm{MW})$ is the microwave power input $(120 \mathrm{~W})$, $\mathrm{m}$ the total liquid mass (0.025-0.035 kg), Cp(DMA) the specific heat capacity of the solvent, dimethylacetamide, $(2.01 \mathrm{~kJ} / \mathrm{kg} / \mathrm{K})$, $\Delta \mathrm{T} / \Delta \mathrm{t}$ the temperature increase over the heating time (in $\mathrm{K} / \mathrm{s}$ ) and $\mathrm{Q}(\mathrm{Cu}$ ) the microwave energy absorption by the copper.

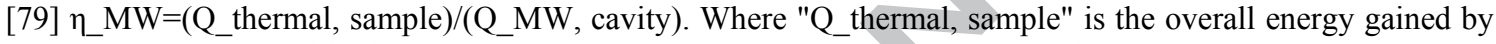
the sample (contributed by liquid and solid absorption) and "Q_MW, cavity" is the total microwave power input to the cavity.

[80] M. Komorowska, G.D. Stefanidis, T. Van Gerven, A.I. Stankiewicz, Influence of microwave irradiation on a polyesterification reaction, Chemical Engineering Journal, 155 (2009) 859-866.

[81] A.C. Metaxas, R.J. Meredith, in: P. Peregrinus (Ed.) Industrial microwave heating, 1993, Chapter 12, pp 296.

[82] D. Grandjean, V. Pelipenko, E.D. Batyrev, J.C. van den Heuvel, A.A. Khassin, T.M. Yurieva, B.M. Weckhuysen, Dynamic $\mathrm{Cu} / \mathrm{Zn}$ Interaction in $\mathrm{SiO} 2$ Supported Methanol Synthesis Catalysts Unraveled by in Situ XAFS, The Journal of Physical Chemistry C, 115 (2011) 20175-20191.

[83] J.D. Grunwaldt, A.M. Molenbroek, N.Y. Topsøe, H. Topsøe, B.S. Clausen, In Situ Investigations of Structural Changes in $\mathrm{Cu} / \mathrm{ZnO}$ Catalysts, Journal of Catalysis, 194 (2000) 452-460. 
Figure 1. Temperature profiles for conventional (surface) and microwave (volumetric) heating (a) shows major benefits at mm-to-cm scale reactors. Nevertheless an important balance must be struck between fast energy supply by the microwaves and fast heat release owing to the microand milli-reactor dimensions $(b)$.

Scheme 1. The Cu-catalyzed Ullmann-type coupling reaction towards 4-phenoxypyridine.

Figure 2. The catalyst coating procedure for fixed-bed and wall-coated catalytic reactors. $C u$ nanoparticles were deposited on a $\mathrm{ZnO}$ nanowire support in the wall-coated reactor, and on a $\mathrm{TiO}_{2}$ support in the fixed-bed reactor.

Figure 3. A schematic process flow diagram of the oil-bath heated and multimode heated microwave setups.

Figure 4. $\mathrm{ZnO}$ nanowires grown on the $\mathrm{SiO}_{2}$ reactor wall show a highly disperse nanowire film in low (a) and high (b) magnification SEM images. Reactor wall becomes covered with byproduct $\mathrm{KCl}(\mathrm{c})$, which could be partially removed (d) by thermal treatment and reduction with hydrogen.

Figure 5. SEM images of the fresh (a) and spent (b) $\mathrm{Cu} / \mathrm{TiO}_{2}$-coated glass beads, demonstrating considerable deposition of $\mathrm{KCl}$ by-product. Catalyst deposition (c) also shows relatively low catalyst density for the $\mathrm{Cu} / \mathrm{TiO}_{2}$ when compared to that of the $\mathrm{Cu} / \mathrm{ZnO}$ system.

Figure 6. Representative TEM images of fresh (a) and spent (c) catalysts used in the $\mathrm{Cu}_{\mathrm{TiO}}$ fixed-bed reactor and the fresh $(b)$ and spent $(d)$ catalyst used in the Cu/ZnO wall-coated reactor.

Figure 7. Losses of $\mathrm{Cu}$ catalyst and $\mathrm{TiO}_{2}$ support for the fixed-bed reactor (a) and of Cu catalyst and $\mathrm{ZnO}$ support for the wall-coated reactor $(b)$ during time-on processing.

Figure 8. Yield vs. time for batch-type experiments using microwave heating and oil-bath heating at (a) $110^{\circ} \mathrm{C}$, (b) $120^{\circ} \mathrm{C}$ and (c) $140{ }^{\circ} \mathrm{C}$. At lower powers, microwave heating has the benefit of selectively heating the metal catalyst. At higher powers, microwave absorption by the solvent removes this advantage. 
Figure 9. Temperature profiles (a) and initial heating rates/arcing frequencies (b) at various powdered Cu loadings, demonstrating increased initial heating rates (for one minute) at low $\mathrm{Cu}$ levels. Decay in heating rates is mainly due to arcing effects at increased Cu loadings.

Figure 10. Performance as a function of residence time for continuous fixed-bed $(\diamond)$, wall-coated $(\Delta)$ and slurry-type continuous reactors (०) shown with reference to the slurry-type batch reactor ( $\square$ ). The 4-chloropyridine and potassium phenolate concentrations were kept at 1.0 and $1.5 \mathrm{~mol} / \mathrm{L}$ at $130{ }^{\circ} \mathrm{C}$ for all experiments. For batch operation, the catalyst loading was 2.5 $m g / m L_{\text {reactor }}$ and the stirring rate was $500 \mathrm{rpm}$. For continuous operations, a catalyst loading of $1.2 \mathrm{mg} / \mathrm{mL}_{\text {reactor }}$ and a flow rate of $10-40 \mathrm{~mL} / \mathrm{hr}$ were applied.

Figure 11. $\mathrm{Cu} / \mathrm{TiO}_{2}$ fixed-bed catalytic performance for a fresh catalyst (non-calcined ( $\left.\square\right)$ and calcined $(\diamond)$ at $350^{\circ} \mathrm{C}$ for $\left.12 \mathrm{~h}\right)$.

Figure 12. Catalytic performance of fresh $\mathrm{Cu} / \mathrm{TiO}_{2}$ fixed-bed catalyst calcined at $350{ }^{\circ} \mathrm{C}(\square)$ and regenerated catalyst calcined at $350^{\circ} \mathrm{C}(\diamond)$ for $12 \mathrm{~h}$.

Figure 13. Performance of the $\mathrm{Cu} / \mathrm{ZnO}$ wall-coated reactor after calcination of fresh catalyst ( $\square)$ and regeneration of spent catalyst $(\diamond)$ at $350^{\circ} \mathrm{C}$ for $12 \mathrm{~h}$. Calcination of fresh catalyst for $24 \mathrm{~h}$ at $350{ }^{\circ} \mathrm{C}$ showed an impressive yield increase to $61 \%(\Delta)$ and regeneration of spent catalyst under similar conditions provided a yield of $57 \%(0)$, demonstrating the importance of the calcination time.

Figure 14. Catalytic performance of the $\mathrm{Cu} / \mathrm{TiO} \mathrm{O}_{2}$ fixed-bed (०) and the $\mathrm{Cu} / \mathrm{ZnO}$ wall-coated ( $\Delta$ ) reactors for four consecutive runs with a residence time $(\tau)$ of $71 \mathrm{~min}$ (calcination: $24 \mathrm{~h}, 200{ }^{\circ} \mathrm{C}$ ).

Figure 15. Reactor designs for microwave-assisted flow-chemistry. A coiled fixed-bed reactor was used in a multi-mode microwave system (a) and a tubular fixed-bed reactor was applied in a single-mode microwave system (b). Input powers are given in green and temperature profiles inside the catalyst beds are in red.

Figure 16. A comparison of single-mode and multi-mode microwave cavities for a conventional $\mathrm{Cu} / \mathrm{TiO}_{2}$ fixed-bed catalyst (a) shows almost a three-fold yield increase for the single-mode microwave cavity due the high and uniform field density achieved. However, these yields were almost doubled (b) using a CuZn catalyst. 
Table 1 . Reactor productivity for catalysts calcined at $350{ }^{\circ} \mathrm{C}$ for $12 \mathrm{hr}$.

\begin{tabular}{lcc}
\hline & \multicolumn{2}{c}{ Average productivity $\left(\mathrm{kg}_{\text {prod }} /\left(\mathrm{m}_{\mathrm{R}}{ }^{3} \cdot \mathrm{h}\right)\right)^{\mathrm{b}}$} \\
\cline { 2 - 3 } & $\mathrm{Cu} / \mathrm{ZnO}$ wall-coated reactor & $\mathrm{Cu} / \mathrm{TiO}_{2}$ fixed-bed reactor \\
\hline Fresh $^{\mathrm{a}}$ & $28.3 \pm 1.9$ & $55.1 \pm 2.4$ \\
Regenerated $^{\mathrm{a}}$ & $20.1 \pm 2.2$ & $37.3 \pm 1.2$ \\
\hline
\end{tabular}

a) $6 \mathrm{~h}$ time-on-process for both fresh and regenerated catalyst

b) Referring to the volume of empty tubes for both reactors 


\section{Figure 1}

Surface versus Microwave heating

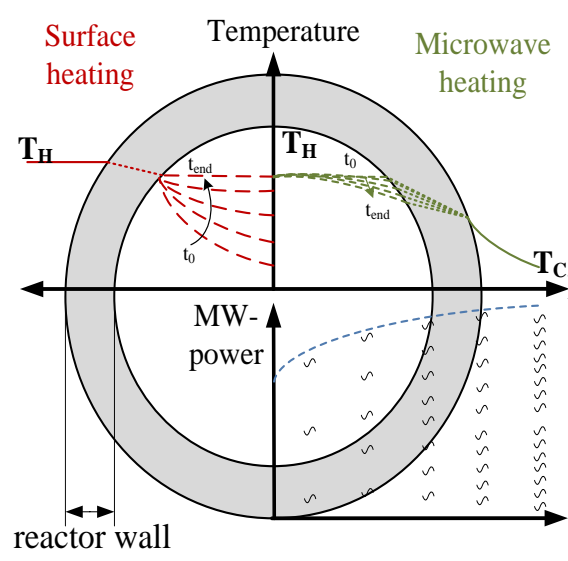

a) $(\sim \mu \mathrm{m})$
Milli reactors versus Microwave heating

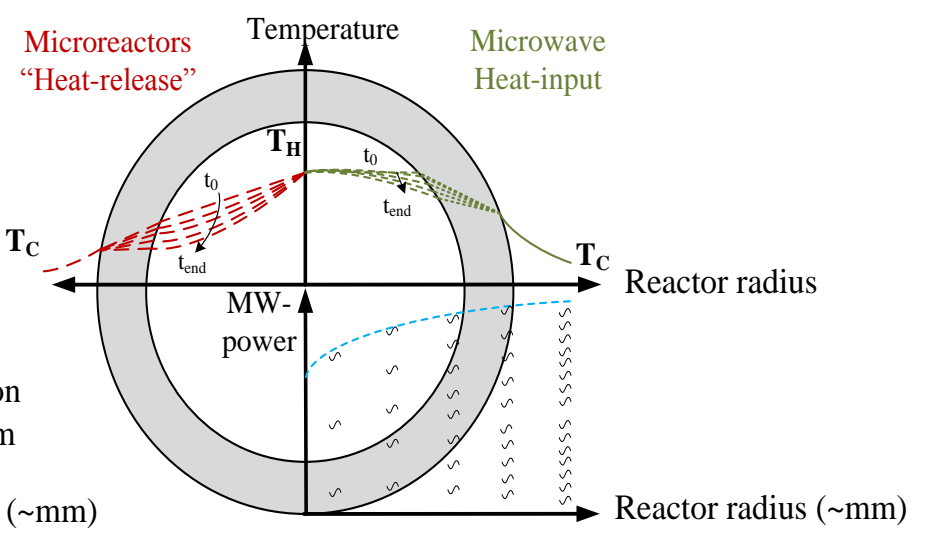

b) 


\section{Scheme 1}

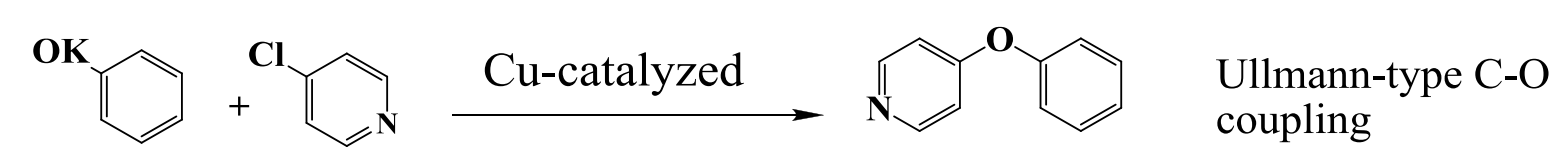




\section{Figure 2}

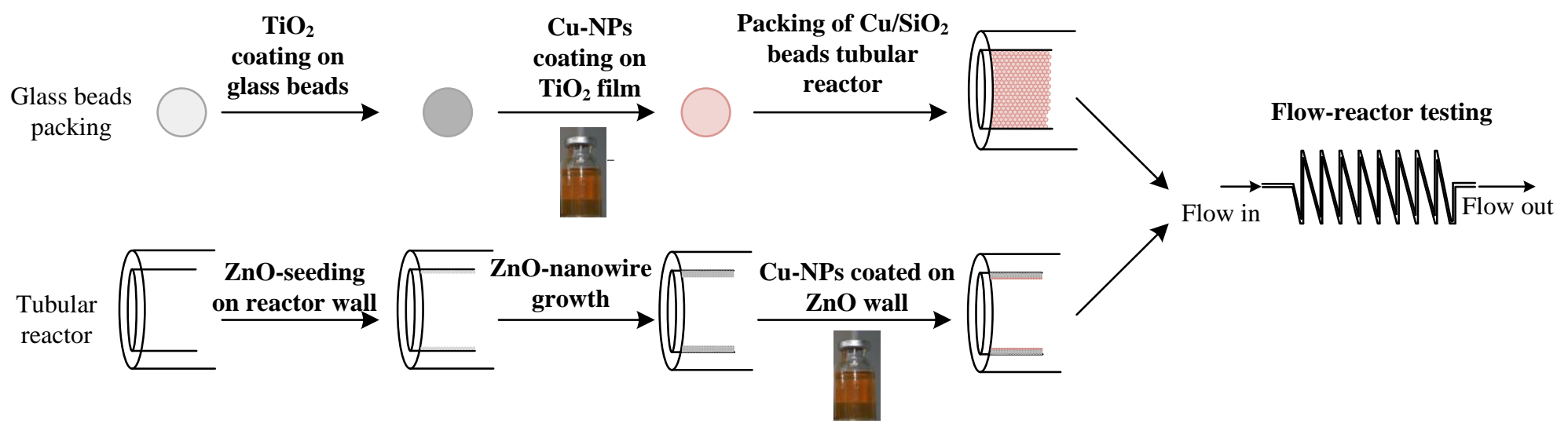

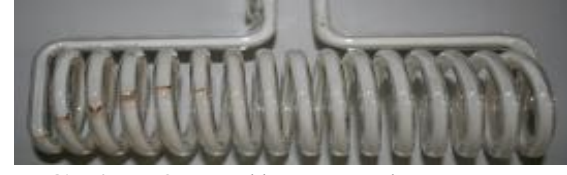

$\mathrm{Cu} / \mathrm{ZnO}$ wall-coated reactor

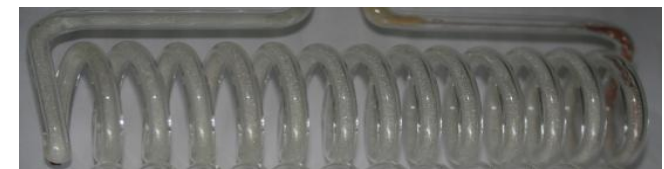

$\mathrm{Cu} / \mathrm{TiO}_{2}$ fixed-bed reactor 


\section{Figure 3}

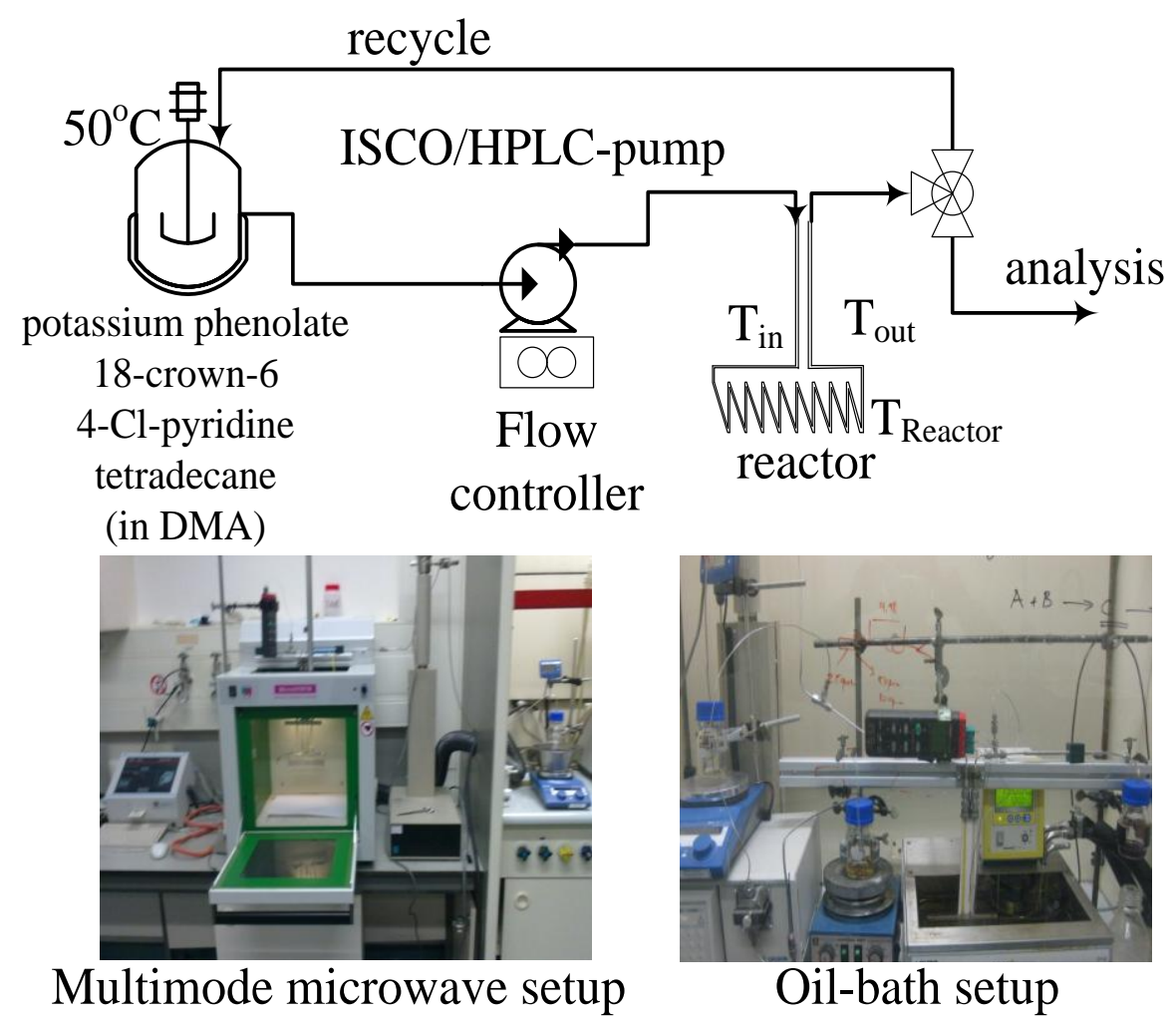




\section{Figure 4}
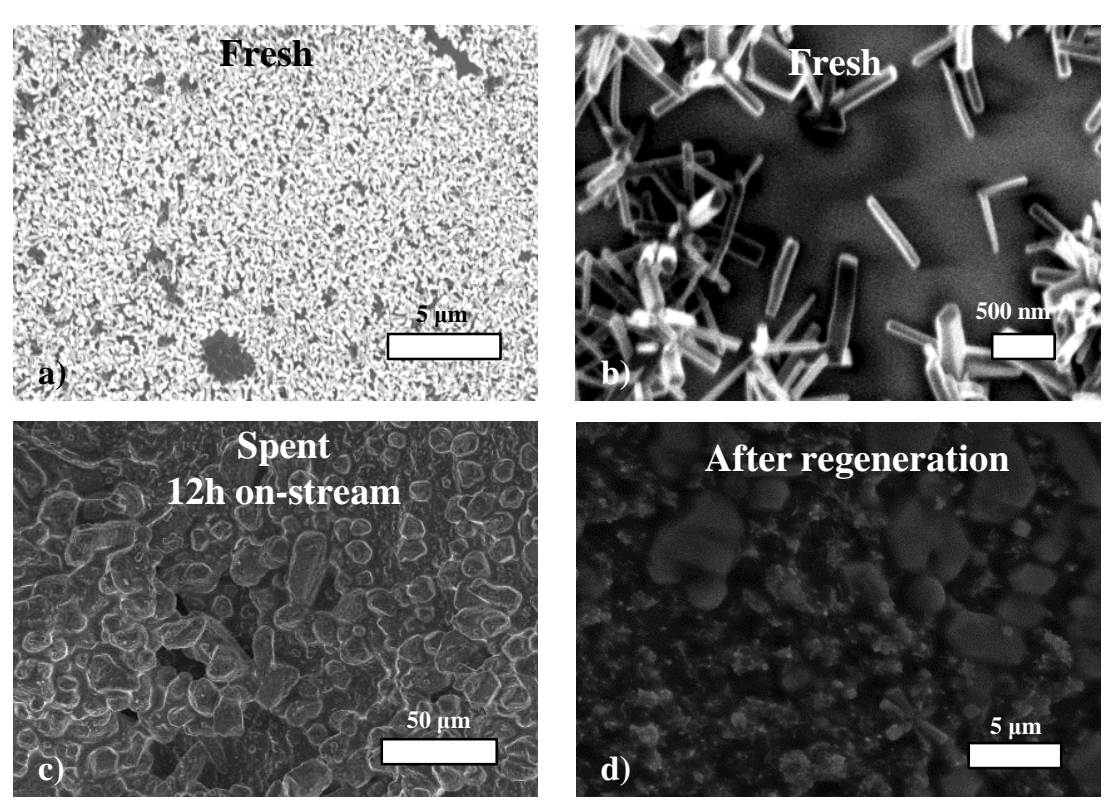


\section{Figure 5}

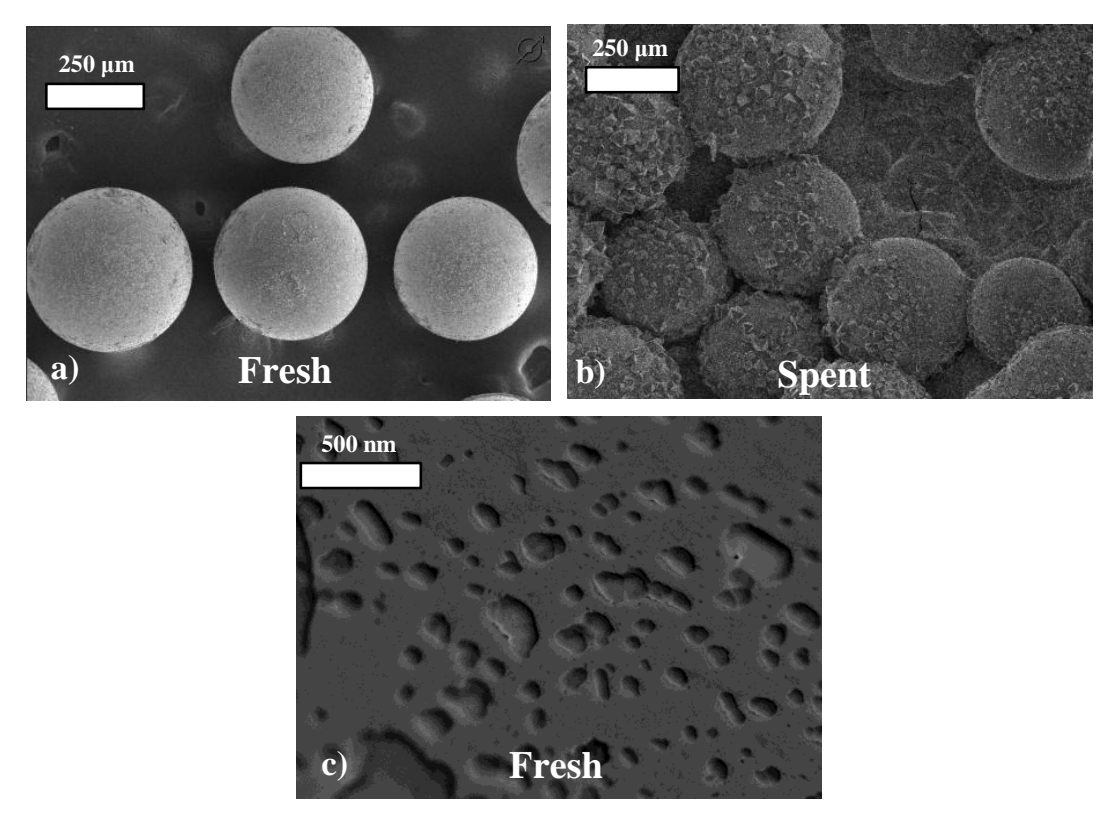




\section{Figure 6}

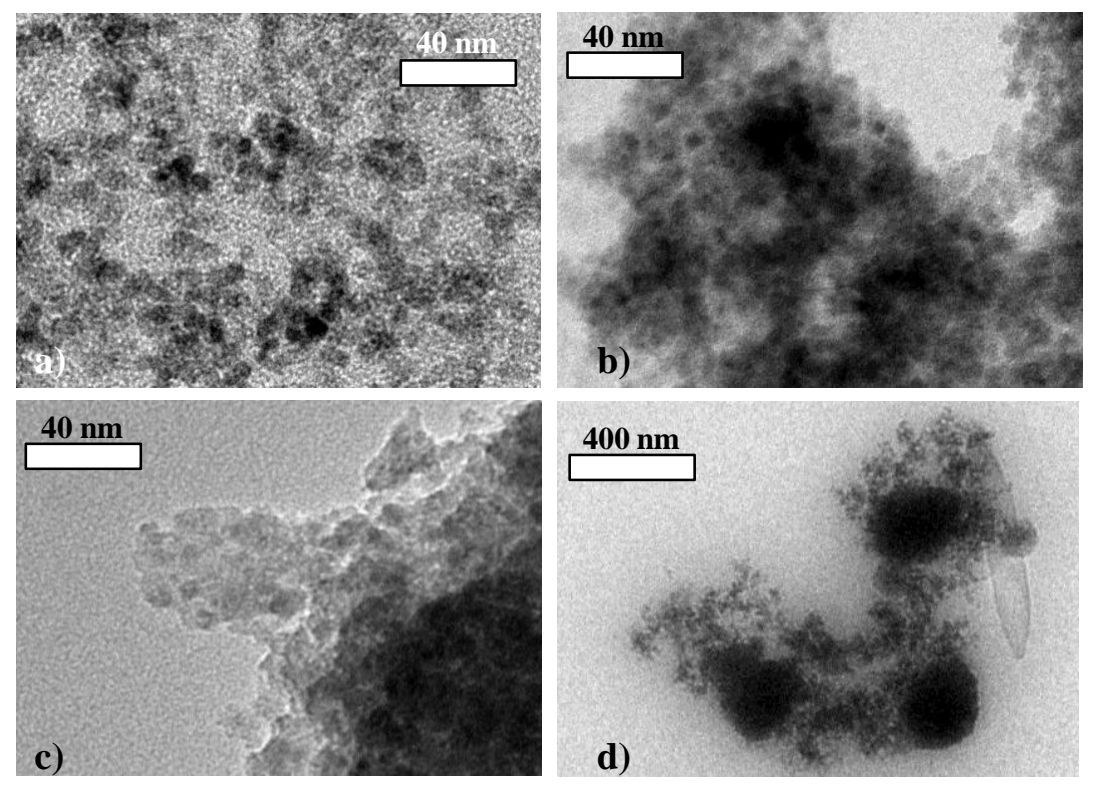




\section{Figure 7}
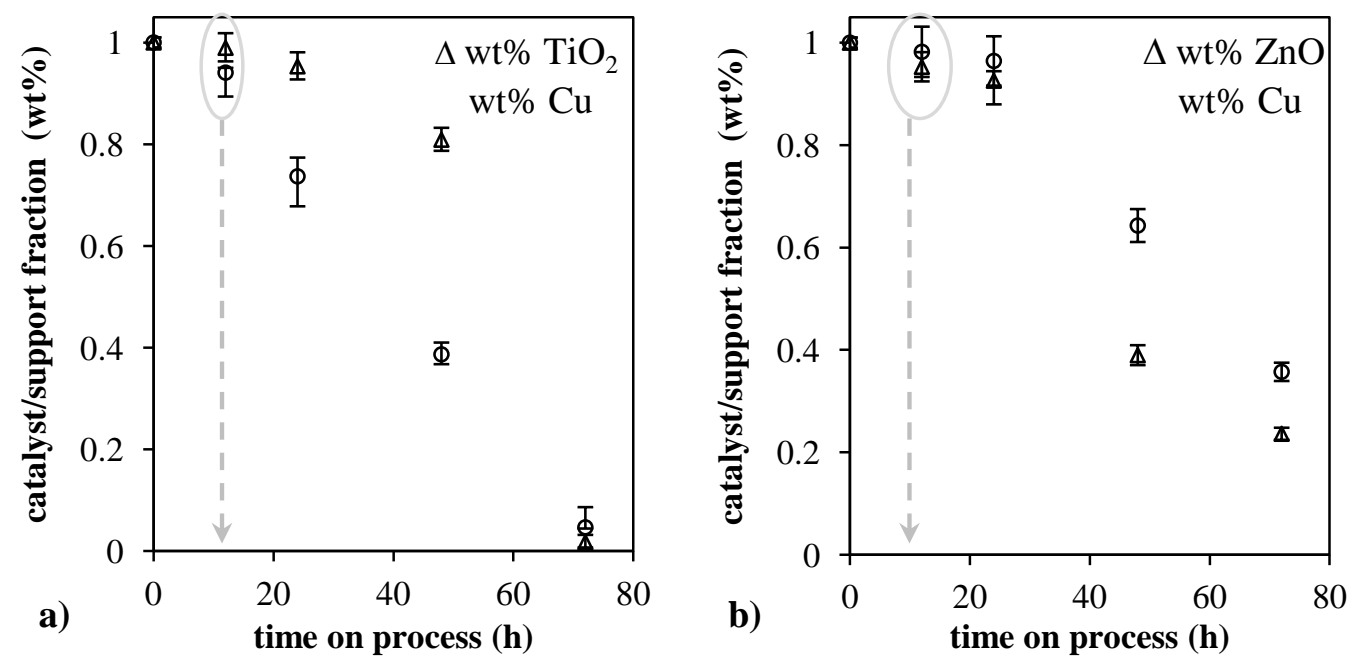


\section{Figure 8}
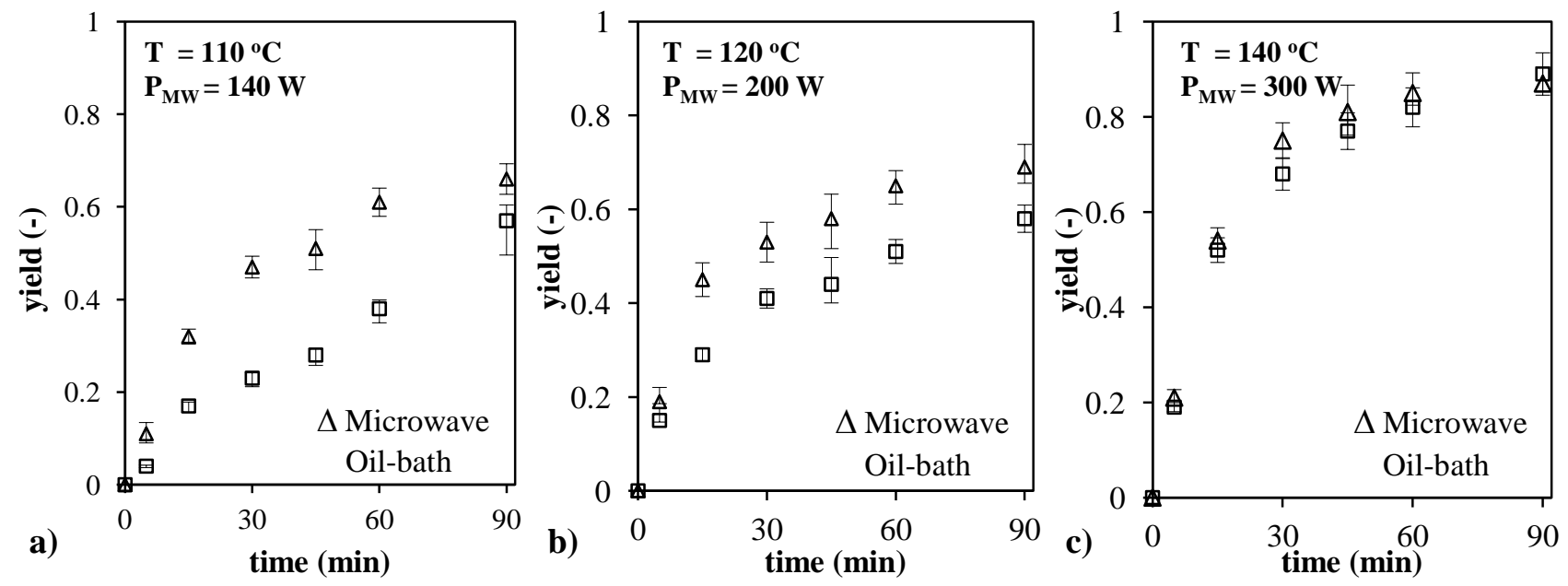


\section{Figure 9}
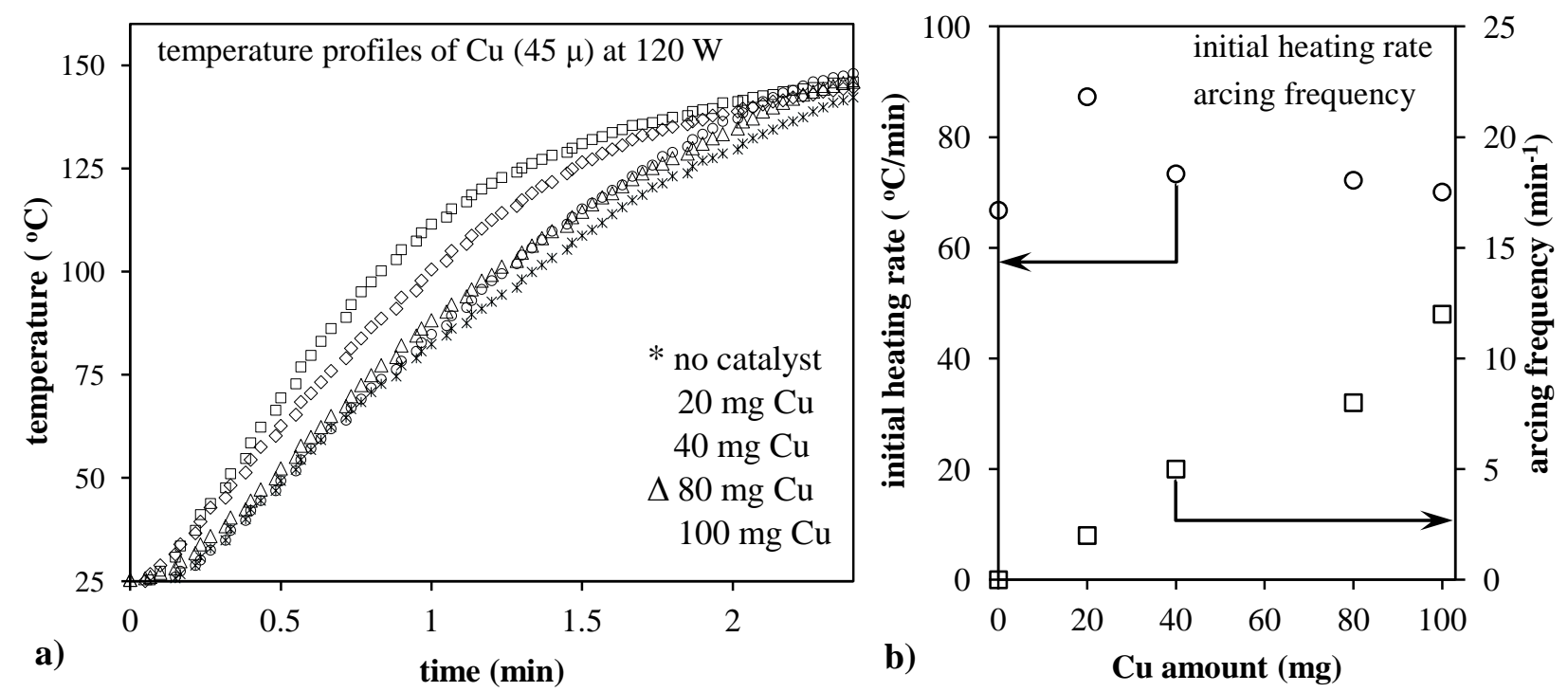


\section{Figure 10}

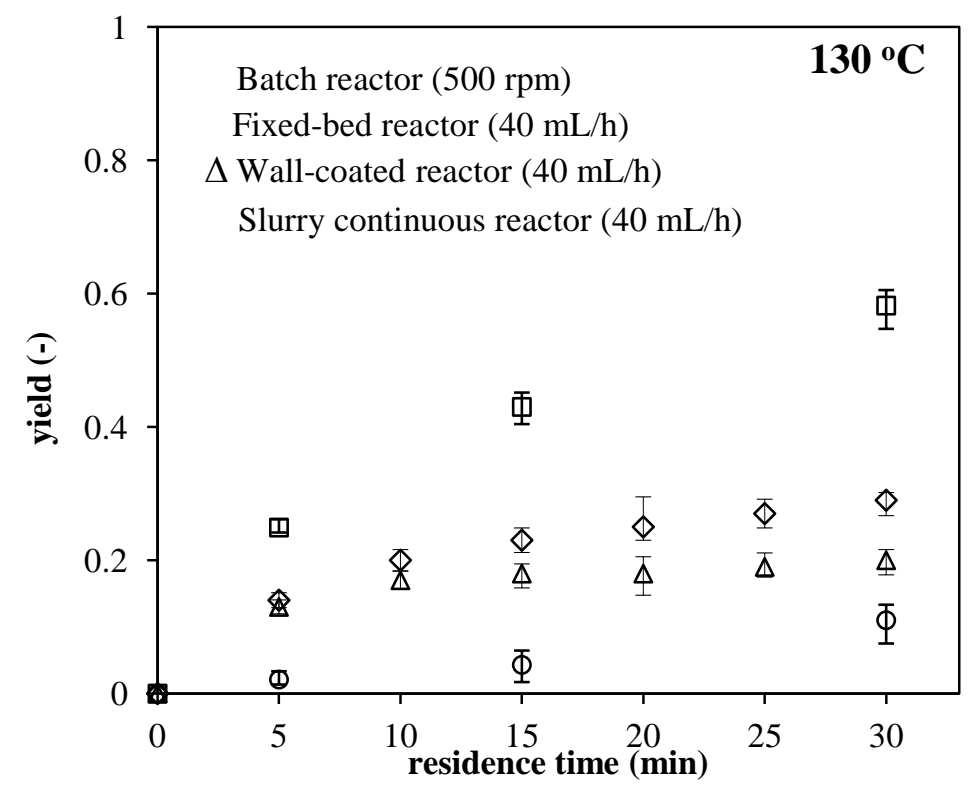




\section{Figure 11}

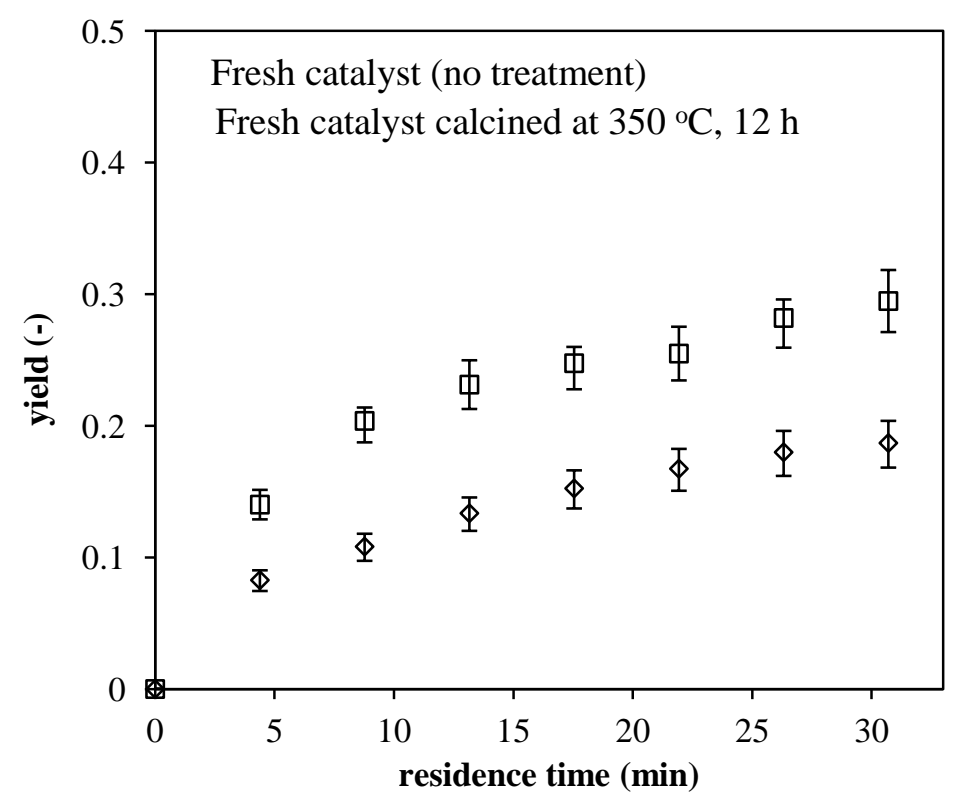




\section{Figure 12}

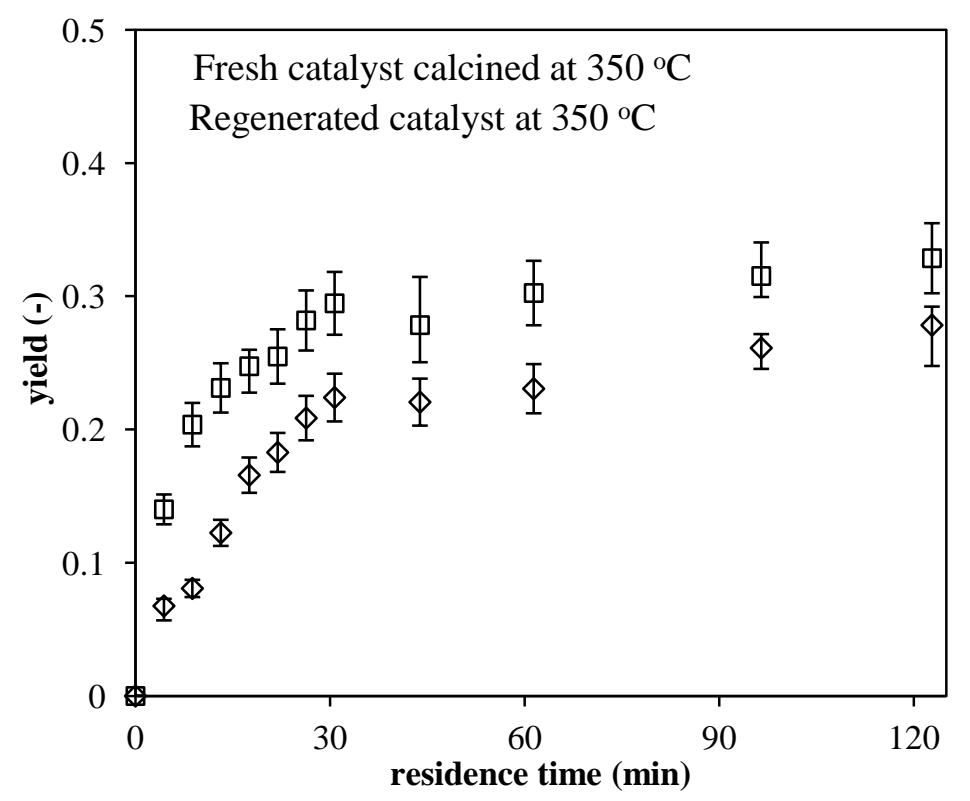




\section{Figure 13}

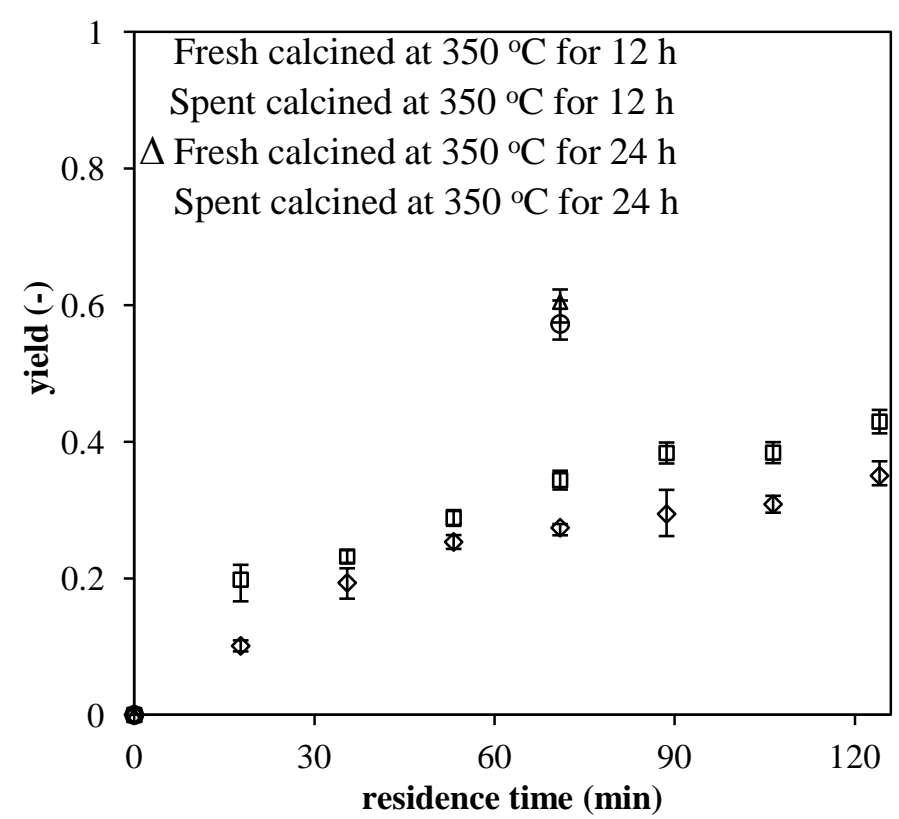




\section{Figure 14}

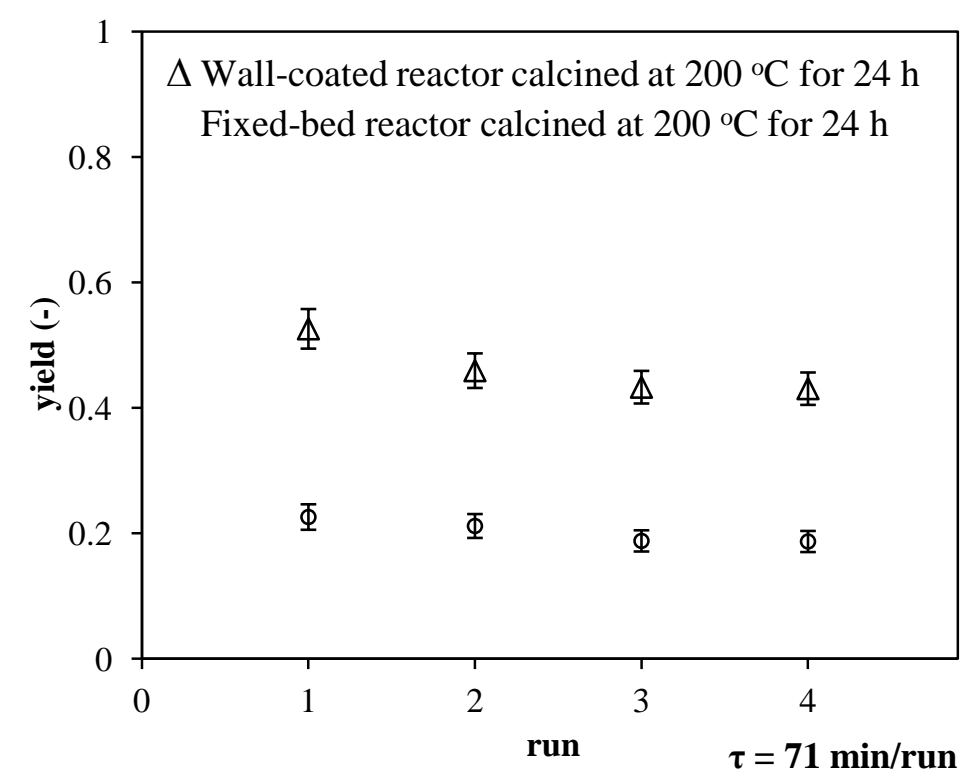




\section{Figure 15}

a)
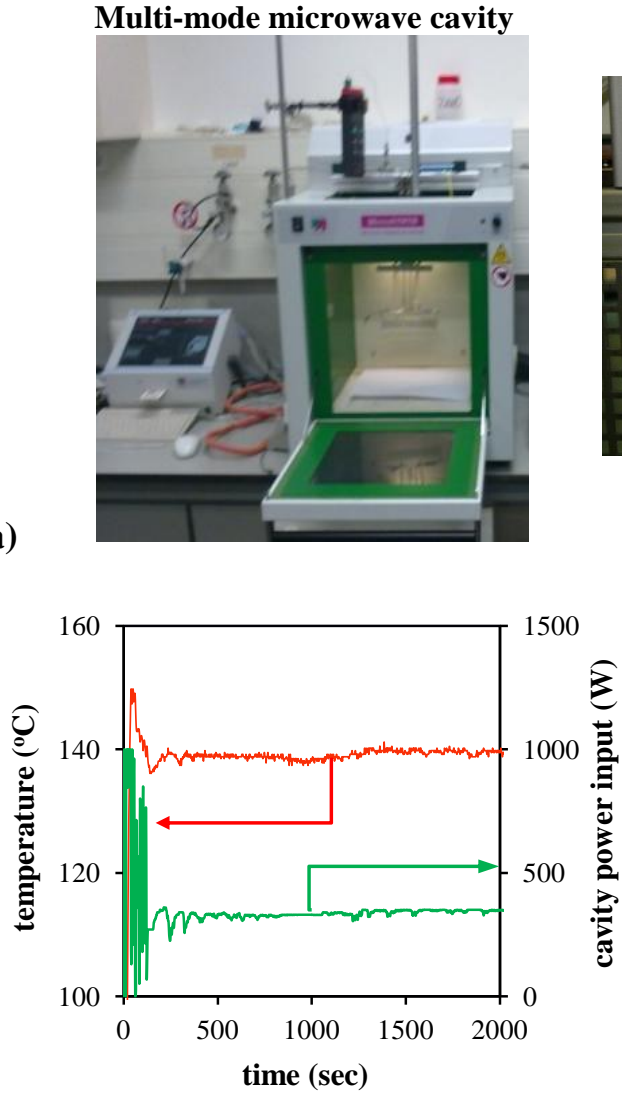

Single-mode microwave cavity

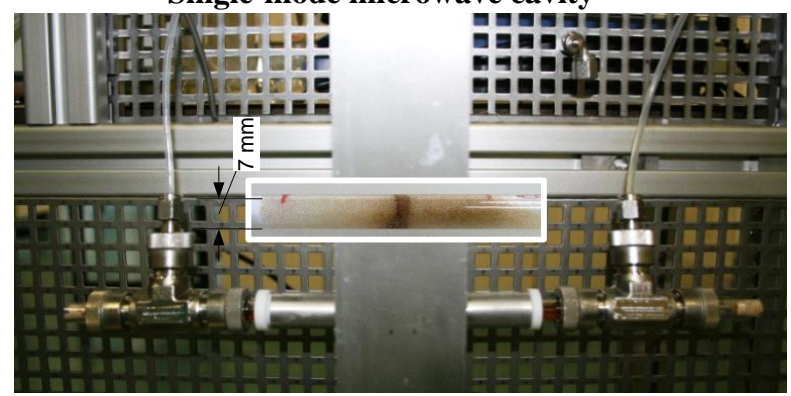

b)

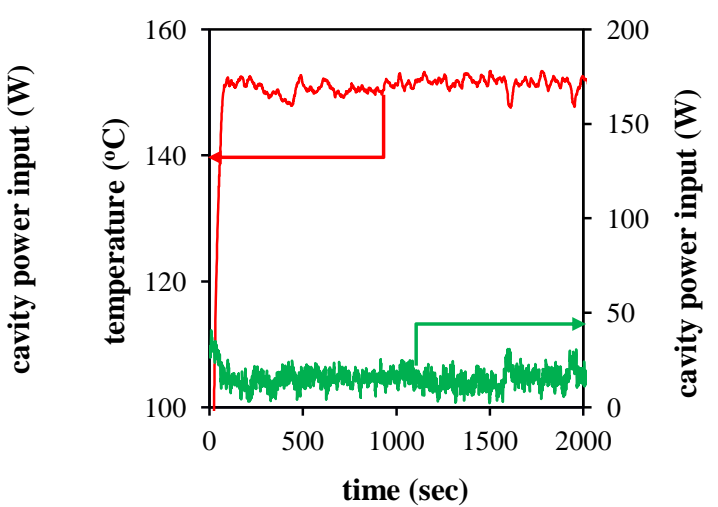




\section{Figure 16}
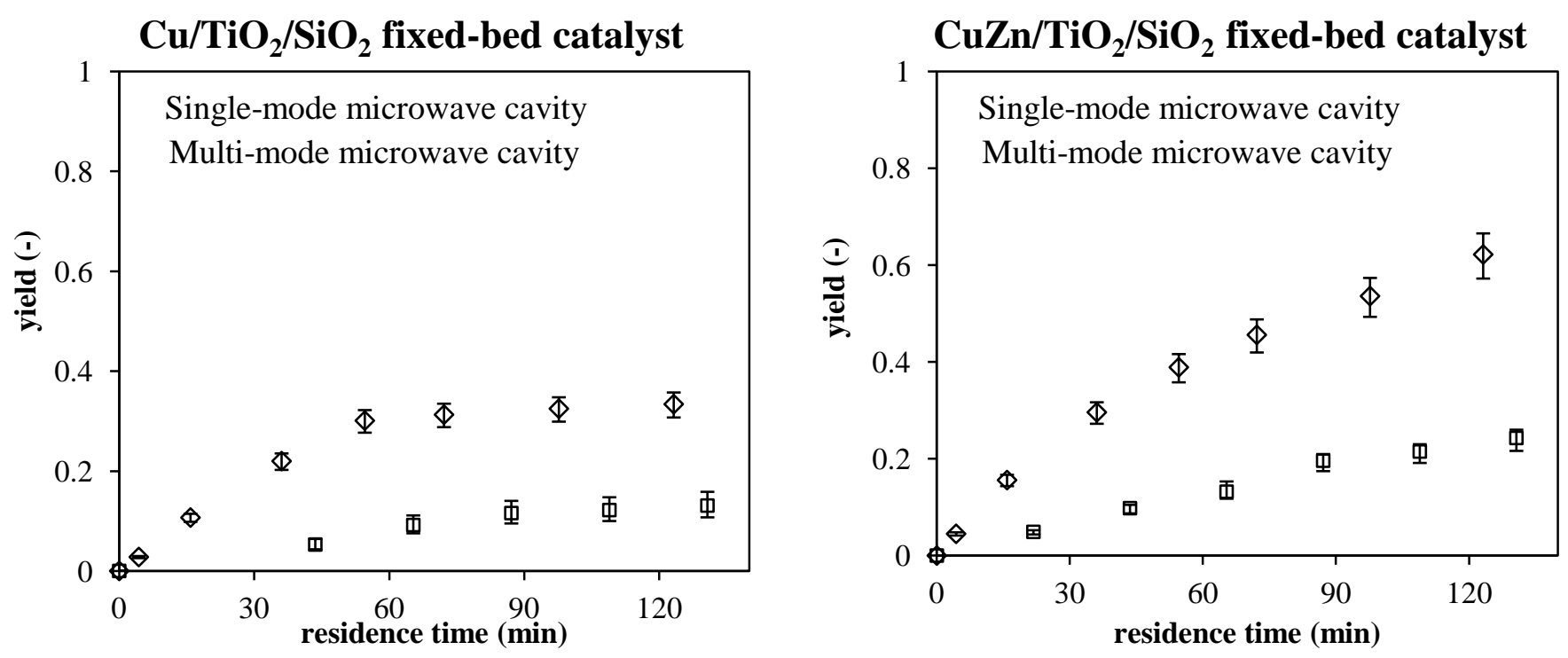


\section{Highlights}

Active $\mathrm{Cu}$ nanocatalyst was applied in the microwave flow-type Ullmann C-O coupling

Added value of single-mode over multi-mode microwaves is investigated and discussed

We propose nano- $\mathrm{Cu}$ stable against arcing for sustainable microwave applications

We investigate the major causes and solution in destructive microwave metal arcing 